\title{
Impact of synthetic abyssal hill roughness on resolved motions in numerical global ocean tide models
}

\author{
Patrick G. Timko ${ }^{\mathrm{a}, \mathrm{b}, \mathrm{c}, *}$, Brian K. Arbic ${ }^{\mathrm{b}}$, John A. Goff ${ }^{\mathrm{c}}$, Joseph K. Ansong ${ }^{\mathrm{b}}$, \\ Walter H.F. Smith ${ }^{\mathrm{d}}$, Angélique Melet ${ }^{\mathrm{eff}}$, Alan J. Wallcraft ${ }^{\mathrm{g}}$ \\ a School of Ocean Sciences, Bangor University, Menai Bridge, Wales United Kingdom \\ ${ }^{\mathrm{b}}$ Department of Earth and Environmental Sciences, University of Michigan, Ann Arbor, MI, USA \\ cInstitute for Geophysics, University of Texas at Austin, Austin, TX, USA \\ ${ }^{\mathrm{d}}$ National Environmental Satellite, Data, and Information Service, National Oceanic and Atmospheric Administration, Silver Spring, MD, USA \\ e LEGOS, University of Toulouse, CNES, CNRS, IRD, UPS, Toulouse, France \\ ${ }^{\mathrm{f}}$ Mercator-Océan, Ramonville St-Agne, France \\ ${ }^{g}$ Oceanography Division, Naval Research Laboratory, Stennis Space Center, MS, USA
}

\section{A R T I C L E I N F O}

\section{Article history:}

Received 28 November 2016

Revised 14 February 2017

Accepted 23 February 2017

Available online 27 February 2017

\section{Keywords:}

Abyssal hills

Internal tides

Global ocean model

Tidal energy conversion

\begin{abstract}
A B S T R A C T
Global models of seafloor topography have incomplete and inconsistent resolution at horizontal wavelengths less than about $10-20 \mathrm{~km}$, notably due to their inability to resolve abyssal hills in areas unsurveyed by ships (that is, about $90 \%$ of the global seafloor). We investigated the impact of this unresolved bottom roughness on global numerical simulations of the HYbrid Coordinate Ocean Model (HYCOM) that are forced exclusively by the M2 and K1 internal tides. Simulations were run with horizontal resolutions of $0.08^{\circ}$ and $0.04^{\circ}, 10$ isopycnal layers in the vertical direction, and two versions of bathymetry: one derived from the SRTM30_PLUS global bathymetry model, and one merging SRTM30_PLUS with a synthetic fractal surface simulating the expected roughness of abyssal hills in the $2-10 \mathrm{~km}$ horizontal wavelength band. Power spectra of the two bathymetry versions diverge at wavenumbers of order $4^{*} 10^{-4}$ radians $/ \mathrm{m}$ and higher (wavelengths of order $15 \mathrm{~km}$ and lower), with more pronounced differences evident on the $0.04^{\circ}$ grid, as the $0.08^{\circ}$ grid has a more limited ability to capture bathymetric details at the abyssal hill scale. Our simulations show an increase in the amount of kinetic and potential energy in higher vertical modes, especially in the $0.04^{\circ}$ simulation, when the synthetic roughness is added. Adding abyssal hills to the $0.04^{\circ}$ simulation increases the $\mathrm{M}_{2}$ kinetic energy for modes 3 and 4 by $12-18 \%$ and the potential energy by $5-15 \%$. Adding abyssal hills to the $0.08^{\circ}$ simulation yields a reduced, though still measurable, impact on simulated baroclinic tidal energies. Baroclinic tidal energy conversion rates increase by up to $16 \%$ in regions of high roughness, and by up to $3.4 \%$ in the global integral. The $3.4 \%$ increase in global conversion rates in the numerical simulations is less than the $10 \%$ increase computed from a linear analysis on a $0.008^{\circ}$ grid because of the resolution limitations of the numerical simulations. The results obtained in the present study, though limited by the horizontal and vertical resolutions of the simulations, are consistent with those of previous studies indicating that abyssal hills on the seafloor transfer energy into higher vertical mode internal tides. The method employed here to add synthetic roughness could easily be replicated in other models, with higher resolution and/or more complex forcing.
\end{abstract}

(C) 2017 Elsevier Ltd. All rights reserved.

\section{Introduction}

This paper proposes a method to account for unresolved smallscale seafloor roughness in ocean models. Seafloor roughness impacts oceanic flows in a variety of ways. To name one example, barotropic tidal flows over rough topography generate baroclinic

\footnotetext{
* Corresponding author.

E-mail address: ptimko@umich.edu (P.G. Timko).
}

tides which ultimately break, resulting in turbulence and mixing (Munk and Wunsch, 1998; Egbert and Ray, 2000, 2001, 2003). One of the limiting factors in ocean models, especially global ocean models, is the availability of high-resolution bathymetry data. For a regional model of limited geographic area, survey data of sufficiently high resolution may exist already or may even in some cases be captured in a new survey. However, on a global scale, at 1 minute resolution only $10 \%$ of the ocean floor has been mapped acoustically (Wessel and Chandler, 2011) and most of the regions mapped are coastal (Charette and Smith, 2010). At 
present, global bathymetric datasets such as the GEBCO_08 Grid (http://www.gebco.net) and SRTM30_PLUS (Becker et al., 2009; Sandwell and Smith, 2009) are available at resolutions of 30 arc seconds. However, many of the ocean depth values represented in global bathymetric datasets are estimated from satellite altimetry data, which is less accurate than acoustic soundings (Becker et al., 2009; Smith and Sandwell, 1994, 1997, 2004; Sandwell and Smith, 2009). Altimetry-based datasets are able to resolve features with horizontal wavelengths of order $10-20 \mathrm{~km}$ or larger, but they are not able to accurately map the structure of abyssal hills, which have characteristic length scales of $2-10 \mathrm{~km}$, and which cover a large fraction of the seafloor, though not all of it (Goff and Jordan, 1988). Abyssal hill roughness is important because it generates substantial amounts of energy in high vertical mode internal gravity waves, which are more conducive to breaking and mixing than low-mode waves.

To account for the abyssal hill roughness missing in global bathymetry datasets, Goff and Arbic (2010) produced a synthetic global map of seafloor roughness based upon sediment thickness, seafloor spreading rates and ridge orientation. The Goff and Arbic (2010) map is based on a band-limited fractal model, whose parameters are taken from empirically-derived relationships with spreading rates and sediment thickness. Goff (2010) produced a map of one characteristic of seafloor roughness-the rootmean-square height-based upon satellite altimeter measurements. As discussed in Section 2 the Goff and Arbic (2010) and Goff (2010) synthetic roughness maps (or equivalent spectral representations) have been used in several studies that employ either a linear analytical model, or a parameterization inserted into a numerical model, to estimate energy conversion rates into internal tides or internal lee waves. None of the previous studies that have used the roughness maps feature numerically resolved internal gravity waves that are directly generated by the added roughness. In this paper, we examine the impacts of synthetic abyssal hill roughness on the resolved motions in global internal tide models.

For simplicity, the tide models employed in the present study are forced only by the astronomical tides; they are not simultaneously forced by atmospheric fields. We use global models because they enable us to examine the influence of abyssal hill roughness in different ocean basins, and because we are interested in the impact of abyssal hills on the global energy flux into internal tides, the latter being a topic of great ongoing interest in the community. The horizontal resolutions used in the simulations presented here are at the level of the state-of-the-art used in present highresolution ocean models (e.g., Hecht and Hasumi, 2008). We employ a representative realization of the synthetic abyssal hill roughness map of Goff and Arbic (2010), averaged to the same 30 arc second grid used in SRTM30_PLUS. The realization is added to the SRTM30_PLUS bathymetry and then interpolated onto global ocean model grids of resolutions $1 / 12.5^{\circ}$ and $1 / 25^{\circ}$ We also interpolate the SRTM30_PLUS bathymetric data without the additional seafloor roughness onto the same $1 / 12.5^{\circ}$ and $1 / 25^{\circ}$ grids. By comparing outputs between model simulations performed with and without the added roughness we are able to estimate the influence that such additional structure has on the generation of internal tides in a global ocean model. We will show that the addition of synthetic abyssal hill roughness increases the barotropic to baroclinic tidal energy conversion rates and the energies in high vertical modes, without significantly impacting the area-averaged accuracy of the barotropic and low-mode baroclinic tides with respect to altimetric constraints. Although the focus of this paper is on global models forced only by tides, the methods we use to add synthetic roughness could easily be employed in higher-resolution regional models, and in models with more complex forcing.

In order to place the current study in context, in Section 2 we present a brief overview of previous studies of global in- ternal tides, and a brief overview of previous uses of the Goff and Arbic (2010) and Goff (2010) abyssal hill roughness fields. In Section 3 we describe the global model configuration and initial conditions, and we provide a detailed description of our procedures for merging the synthetic abyssal hill map with an existing global bathymetry dataset. In Section 4, the overall accuracy of the large-scale barotropic tides and low-mode baroclinic tides in our solution is quantified through computation of the root mean square error of the modeled sea surface heights with respect to highly accurate satellite-altimetry constrained tide models, and through comparison of the internal tide signatures of sea surface heights in our simulations with along-track altimeter data. We also compare the barotropic kinetic energies of our simulations to those in a satellite-altimetry constrained model. In Section 5 we discuss the impacts of the synthetic abyssal hill roughness on the barotropic-to-baroclinic tidal conversion rates, and on the vertical mode structure of the baroclinic tidal energies. The synthetic roughness increases the barotropic to baroclinic tidal energy conversion in a manner that is approximately consistent with the linear analysis results of Melet et al. (2013), but that is limited by the resolution of the numerical simulations. Our results are also compared to the closely related results of Niwa and Hibiya (2011, 2014), who computed the increase in baroclinic tidal energy conversion in models as a function of the model resolution. As in the Niwa and Hibiya papers, we find that model resolution is a critical parameter in global internal tide models. The abyssal hill structure is an additional effect, on top of resolution considerations, that is demonstrated here.

\section{Background}

The conversion of large-scale geostrophic and tidal flows into internal gravity waves is a topic of great recent interest because the mixing that takes place when internal gravity waves break is thought to exert a strong control on the large-scale stratification and overturning circulation of the ocean (e.g., Munk and Wunsch, 1998). The impacts of internal tide mixing, and the dynamics of internal tide generation and propagation, have been examined in a number of recent studies. Exarchou et al. (2012) examined the sensitivity of tidal mixing schemes, and the impact on the general circulation in numerical simulations, to topographic roughness on scales of $15-200 \mathrm{~km}$. The propagation of internal tides away from their generation sites at seafloor ridges has been observed with acoustic tomography (Dushaw et al., 1995) and satellite altimetry (Kantha and Tierney, 1997; Ray and Mitchum, 1996). Egbert and Ray (2000, 2001, 2003) estimated global tidal energy dissipation from altimetry data and concluded that the barotropic tides lose more energy in the deep ocean than can be accounted for by quadratic bottom boundary layer drag in shelf regions. One of the two classes of bottom topography found to be associated with the energy conversion of barotropic to baroclinic tides in the open ocean was small-scale roughness associated with mid-ocean ridges (Egbert and Ray, 2001). Garrett and Kunze (2007) provide a review of developments in the theory of internal tide generation in the deep ocean. The generation of internal tides by barotropic tidal flow over topography has been examined with linear analysis (e.g., Llewellyn Smith and Young, 2002; St. Laurent et al., 2003; Nycander 2005; Falahat et al., 2014), numerical regional ocean models (e.g., Cummins and Oey, 1997; Carter et al., 2012), and numerical global internal tide models (e.g., Arbic et al., 2004; Simmons et al., 2004; Niwa and Hibiya, 2011, 2014). Global internal tide modeling has only begun in the last decade, because internal tides have relatively small horizontal scales $(\sim 100 \mathrm{~km})$ and therefore can only be modeled in simulations with high horizontal resolution, which are expensive to perform on a global scale. 
The topographic roughness maps of Goff and Arbic (2010) and Goff (2010) have been used in several studies of the impact of abyssal hill roughness on oceanic energy budgets and mixing. Melet et al. (2013) combined the synthetic roughness maps, the linear theory of Nycander (2005), and tidal velocities from a dataassimilative barotropic tide model, to estimate the energy flux into internal tides in abyssal hill regions. de Lavergne et al. (2016) and Lefauve et al. (2015) used the Melet et al. (2013) estimate of the abyssal hill related energy flux into internal tides to respectively show that about $25 \%$ of the transformation of Antarctic Bottom Water driven by local internal wave mixing is attributed to internal tides generated at abyssal hills and to estimate a global three-dimensional map of tidal dissipation. Scott et al. (2011; see also Wright et al., 2014) employed the synthetic roughness maps together with linear theory (Bell, 1975) to estimate the globally integrated energy flux from low-frequency geostrophic motions into internal lee waves. In Scott et al. (2011), as in Melet et al. (2013), the background flows are taken from a model that does not incorporate the roughness maps. In Trossman et al. (2013, 2016), the roughness maps serve as inputs to a parameterization of internal lee wave drag (Garner 2005) that is inserted inline into high-resolution simulations of the eddying general circulation. In the Trossman et al. $(2013,2016)$ studies, the vertical structure and amplitudes of eddy kinetic energy are altered in the presence of the parameterized lee wave drag, but the internal lee waves themselves are not generated in the global simulations, which cannot be run at high enough horizontal resolution to resolve lee waves. Finally, Trossman et al. (2015) employed the roughness maps to compare the internal lee wave conversions predicted by the Bell (1975) theory and the Garner (2005) scheme with dissipation rates measured by microstructure profilers in two different Southern Ocean field campaigns. In summary, the Goff and Arbic (2010) and Goff (2010) synthetic roughness fields have been used in two different ways in previous studies-the roughness impacts either a wave drag parameterization that is subsequently inserted into a model of low-frequency flows, or is used as an input for a linear analysis of energy conversion into internal waves (from either tidal or low-frequency flows). In the present study, for the first time, we investigate the impact of abyssal hill roughness on resolved internal wave motions (in this case, internal tides) in numerical models. We use global internal tide models as an example system because of the ongoing interest in global tidal dissipation, and because global tide models are readily available to us. However, the methods employed here to put roughness into ocean models could easily be employed in other contexts, such as very-high-resolution regional models, or models with more complex forcing fields than the tide-only models considered here.

Because we employ numerical models in this study, both the vertical and horizontal resolution of our models are limiting factors in the energy conversion rates we obtain. We keep the number of vertical layers fixed in all of our runs and instead focus on the limitations of horizontal resolution. To explore sensitivities to both vertical and horizontal resolution would have required more computational resources than we had available. Zaron and Egbert (2006) examined the impact of unresolved bathymetry on the convergence and accuracy of a linear numerical model and found that convergence was only achieved if the power spectrum of the bathymetry decayed at a rate greater than $\mathrm{k}^{-2}$, where $\mathrm{k}$ is the horizontal wave number. The influence of horizontal resolution can be examined via comparison of our numerical results with the analytical internal tide conversion study of Melet et al. (2013), which was performed on a much higher resolution grid $\left(1 / 120^{\circ}\right)$ than we are able to use in our global numerical models. At the same time, by simulating the global internal tide field, we can examine the impacts of abyssal hills on the vertical modal structure of the internal tidal energies, and the barotropic tides, properties that were not discussed in Melet et al. (2013). Our results will also be compared to the results of Niwa and Hibiya (2011, 2014), who thoroughly investigated the dependence of barotropic to baroclinic tidal energy conversion on model horizontal resolution in a global model forced only by the astronomical tides. Niwa and Hibiya (2011, 2014) interpolated existing bathymetry data to the different horizontal resolutions. They reported that baroclinic energy conversion rates increased almost exponentially with decreasing horizontal grid spacing and that the conversion rates were very sensitive in regions characterised by small-scale topographic features. Their study indicated that an increase in the global baroclinic conversion rate of $520 \mathrm{GW}$ may be attributed to the resolution of small-scale topographic features that is obtained with a decrease in grid spacing from $1 / 5^{\circ}$ to $1 / 20^{\circ}$ Only $167 \mathrm{GW}$ was attributed to the decrease in grid spacing itself. The increased roughness and consequent increased energy conversion rates seen in the higher-resolution simulations of Niwa and Hibiya are due to better resolution of the roughness in existing global bathymetric datasets. However, these bathymetric datasets do not themselves contain all of the smallscale roughness present in the ocean. The present study differs from the approach of Niwa and Hibiya $(2011,2014)$ in that we merge a synthetic realization of abyssal hills on the seafloor to a global bathymetric dataset prior to interpolating to the model grid. In the limit of very high model resolutions (presently unattainable in global models), our approach would pick up roughness that is missing from current global bathymetric datasets as well as the extra roughness attained through better resolution of the smallscale features that are already present in the global bathymetric datasets.

\section{Model setup and initialization}

\subsection{Initial conditions and model configuration}

We employ the global HYbrid Coordinate Ocean Model (HYCOM; Chassignet et al., 2009) in this study. For simplicity, as in early global baroclinic tide simulations (Arbic et al., 2004; Simmons et al., 2004), we employ a horizontally uniform stratification and a forcing by tides only (i.e., no atmospheric forcing). Our global model domain uses 10 isopycnal layers. The stratification is calculated from averaging the WOCE Data Products Committee (2002) line P15 Conductivity-Temperature-Depth (CTD) data at latitudes $30^{\circ} \mathrm{N}$ and $30^{\circ} \mathrm{S}$. Fig. 1 shows the square of the Brunt-Väisälä frequency, $N^{2}$, calculated from the WOCE data and from the model layers. In the WOCE profile $N^{2}$ has a maximum value of $2.5 \times 10^{-4} \mathrm{~s}^{-2}$ at $50 \mathrm{~m}$ and decreases to $3.6 \times 10^{-5} \mathrm{~s}^{-2}$ at $140 \mathrm{~m}$. The discretization in the 10-layer model yields an underestimated maximum $N^{2}$ value near the surface $(100 \mathrm{~m}$ depth) of $1.2 \times 10^{-4} \mathrm{~s}^{-2}$. Below $2000 \mathrm{~m}, \mathrm{~N}^{2}$ is of order $10^{-6} \mathrm{~s}^{-2}$ in both the WOCE profile and the model, with absolute relative differences between the two being $27 \%$ or less. Each simulation presented in this study is started from rest and forced by tidal constituents $\mathrm{M}_{2}$ and $\mathrm{K}_{1}$. The tidal forcing is ramped up for 5 days after which the simulations are run for 60 days. Self-attraction and loading (Hendershott, 1972) is represented using the scalar approximation (Ray, 1998). Full 3-dimensional global model output is saved at hourly intervals for subsequent harmonic tidal analysis (Foreman, 2004), which is based upon the last 30 days of model output in order to minimize the effects of model spin-up. The horizontally uniform stratification introduces some differences to the actual ocean, in which stratification varies with geographic location due to wind- and buoyancy-forcing. This effect is largest at high latitudes, where the actual stratification is weak. However, the simple tide-only models used here are significantly easier to analyze, and require significantly shorter spin-up times, than internal tide models that include a realistic horizontally varying stratification 


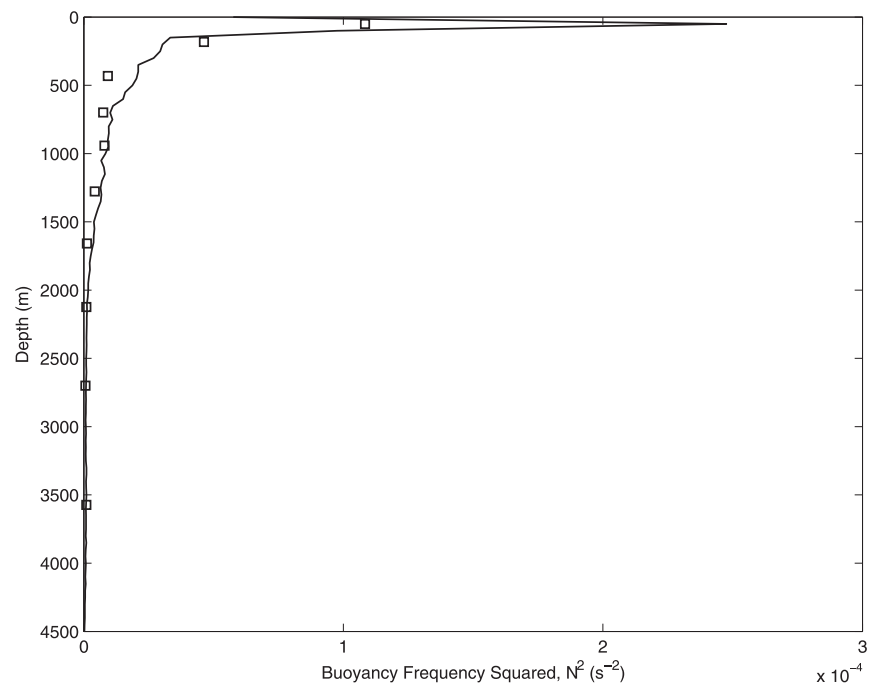

Fig. 1. The square of the Brunt-Väisälä buoyancy frequency, $\mathrm{N}^{2}$ (black curve) calculated from averaging WOCE line P15 data (WOCE Data Products Committee, 2002) at $30^{\circ} \mathrm{N}$ and $30^{\circ} \mathrm{S}$. The black squares indicate the buoyancy frequency of the numerical simulations estimated from the model layers.

driven by the presence of atmospheric forcing concurrent with the tidal forcing (e.g., Arbic et al., 2010, 2012).

Internal tides are directly resolved in the simulations presented in this paper. However, Arbic et al. $(2004,2010)$ argue that global internal tide models must employ a damping-which they take to be in the form of a parameterized topographic internal wave dragto account for energy loss due to internal wave breaking that is unresolved in such models, and hence to attain reasonably accurate tides. Ansong et al. (2015) employed an extensive analysis demonstrating that substantial damping in the open ocean is required in order to accurately model the global internal tide field. The parameterized topographic internal wave drag used here stems from the scheme of Garner (2005) and is tuned to minimize $\mathrm{M}_{2}$ sea surface height errors on the $1 / 12.5^{\circ}$ grid with respect to accurate satellite altimetry constrained models. Because the computational resources required to re-tune the parameterized wave drag at $1 / 25^{\circ}$ were not available at the time this study was conducted, the parameterized wave drag in the $1 / 25^{\circ}$ runs presented here is held constant to the same values used in the $1 / 12.5^{\circ}$ model runs.

The horizontal and vertical resolutions used in this study were chosen to strike a balance between the ability of the model to resolve internal waves and vertical modes of interest and the availability of computational resources. Even with the chosen resolutions, which limit our ability to fully resolve the internal tide fields, the 4 simulations used in this study required approximately 1 million central processing unit (cpu) hours and produced approximately 20 terabytes of raw model output.

\subsection{Model bathymetry}

A radial Blackman filter is used to establish the depth of the ocean at model grid points from ocean bathymetry, STRM30_PLUS, of 30 arc second resolution. Without the additional synthetic roughness, the model bathymetry, $D_{i j}^{S S}$, is given by:

$D_{i j}^{S S}=\frac{\iint S S\left(x^{\prime}, y^{\prime}\right) d\left(x_{i}, y_{j}, x^{\prime}, y^{\prime}\right) d A}{\iint d\left(x_{i}, y_{j}, x^{\prime}, y^{\prime}\right) d A}$,

where $D_{i j}^{S S}=D^{S S}\left(x_{i}, y_{j}\right)$ represents the bathymetry on the model grid, $S S\left(x^{\prime}, y^{\prime}\right)$ is the reference bathymetry, STRM30_PLUS, $d A$ is an

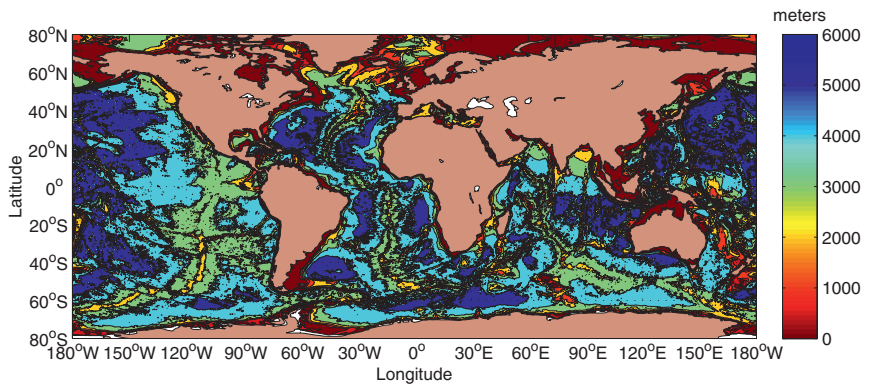

Fig. 2. Model bathymetry at $1 / 12.5^{\circ}$ resolution. Model bathymetry is interpolated from the 30 arc second SRTM30_PLUS bathymetry data using a radial Blackman filter. Depth contours are drawn at 500, 1000, 2000, 3000, 4000, 5000, and $6000 \mathrm{~m}$.

element of area, and $d\left(x_{i}, y_{j}, x^{\prime}, y^{\prime}\right)$ is the radial Blackman filter:

$$
\begin{aligned}
d\left(x_{i}, y_{j}, x^{\prime}, y^{\prime}\right)= & 0.42+0.5 \cos \left(\frac{\pi r\left(x_{i}, y_{j}, x^{\prime}, y^{\prime}\right)}{R}\right) \\
& +0.08 \cos \left(\frac{2 \pi r\left(x_{i}, y_{j}, x^{\prime}, y^{\prime}\right)}{R}\right)
\end{aligned}
$$

Here $R$ is the radius of the filter and $r\left(x_{i}, y_{j}, x^{\prime}, y^{\prime}\right)=$ $\sqrt{\left(x^{\prime}-x_{i}\right)^{2}+\left(y^{\prime}-y_{j}\right)^{2}}$ is the distance between the model grid point, $x_{i}, y_{i}$, and the reference bathymetry grid point, $x^{\prime}, y^{\prime}$. When the model resolution is $1 / 12.5^{\circ}$, the grid resolution is approximately $8.9 \mathrm{~km}$ at the equator and $6.3 \mathrm{~km}$ at $45^{\circ}$ latitude. On the $1 / 25^{\circ}$ grid, the resolution is approximately $4.4 \mathrm{~km}$ at the equator and $3.1 \mathrm{~km}$ at $45^{\circ}$ latitude. For interpolation of the reference bathymetry onto the model grid we use $R=10 \mathrm{~km}$ and $R=5 \mathrm{~km}$ for the $1 / 12.5^{\circ}$ and $1 / 25^{\circ}$ model domains, respectively, so that $R \approx \Delta \mathrm{x}$, where $\Delta \mathrm{x}$ is the gridpoint spacing. The $1 / 12.5^{\circ}$ model bathymetry without the added abyssal hill roughness is shown in Fig. 2.

The STRM30_PLUS dataset includes Survey Identification Data (SID), to indicate locations where the ocean bathymetry is derived from actual acoustic soundings and locations where the bathymetry has been estimated from satellite altimetry data. We convert the SID into a binary map of zeros and ones, with zero indicating estimated bathymetry and one indicating acoustic survey data. From this binary map we create a system of weights to apply to our roughness field, thus preventing the addition of a synthetic roughness field to the model bathymetry in locations for which high-resolution acoustic sounding data, capable of resolving the abyssal hills, is available. The weights, $\alpha_{i j}^{S S}$ are calculated for each point of the 30 arc second grid by:

$\alpha_{i j}^{S S} \equiv \alpha\left(x_{i}^{S S}, y_{j}^{S S}\right)=\frac{\iint B\left(x^{\prime}, y^{\prime}\right) d\left(x_{i}, y_{j}, x^{\prime}, y^{\prime}\right) d A}{\iint d\left(x_{i}, y_{j}, x^{\prime}, y^{\prime}\right) d A}$,

where $B\left(x^{\prime}, y^{\prime}\right)$ is the binary map of observations vs. estimates in the reference bathymetry and $d\left(x_{i}, y_{j}, x^{\prime}, y^{\prime}\right)$ is as defined by (2). The weights are calculated using $R=5 \mathrm{~km}$. The smaller of the two $R$ values used for interpolating the bathymetry values was used in (3) after it was found that using the larger radius strongly influenced the weights, $\alpha_{\mathrm{ij}}$, in regions near the edges between regions of observations/estimates. Fig. 3 provides an example of the generated weights for the North Atlantic, and indicates that even in this well-traversed basin, only a small percentage of the seafloor has been acoustically mapped.

Using the weights generated by (3) we form a second reference bathymetry,

$S S G_{i j}=S S_{i j}+\left(1-\alpha_{i j}\right) G_{i j}$,

where $G_{i j}$ is our synthetic realization of the global abyssal hill statistical model (Goff and Arbic, 2010) at a resolution of 30 arc 


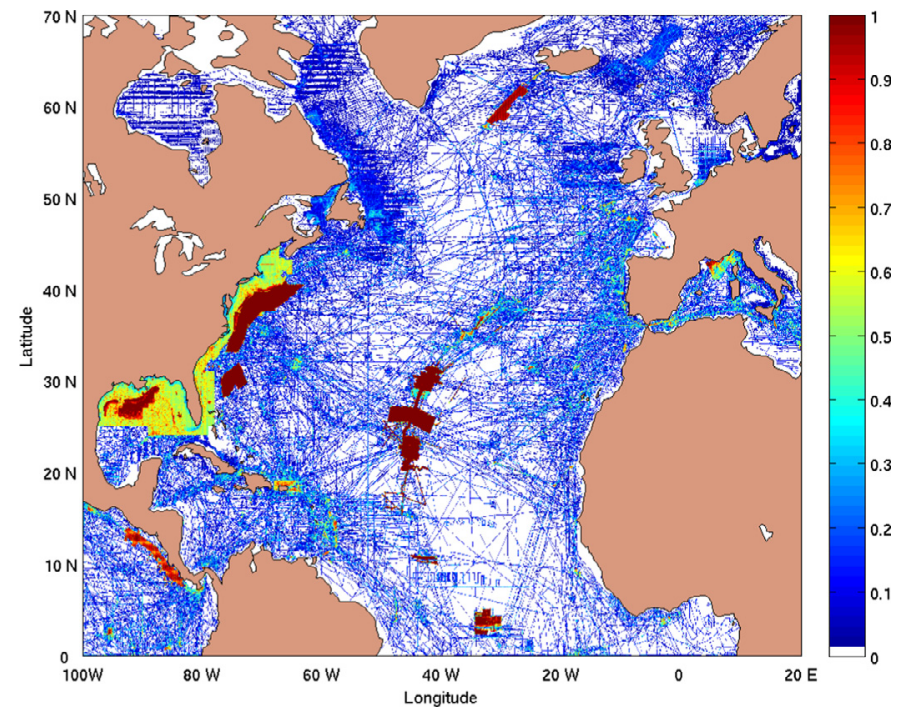

Fig. 3. The weights, $\alpha_{\mathrm{ij}}$, used to interpolate the abyssal hill bottom roughness onto the HYCOM grid. Image resolution is 30 arc seconds and reveals oceanic areas where high-resolution surveys have been conducted (red). Also revealed are ship tracks (blue) and regions where lower resolution survey data is available (yellow). (For interpretation of the references to colour in this figure legend, the reader is referred to the web version of this article.)

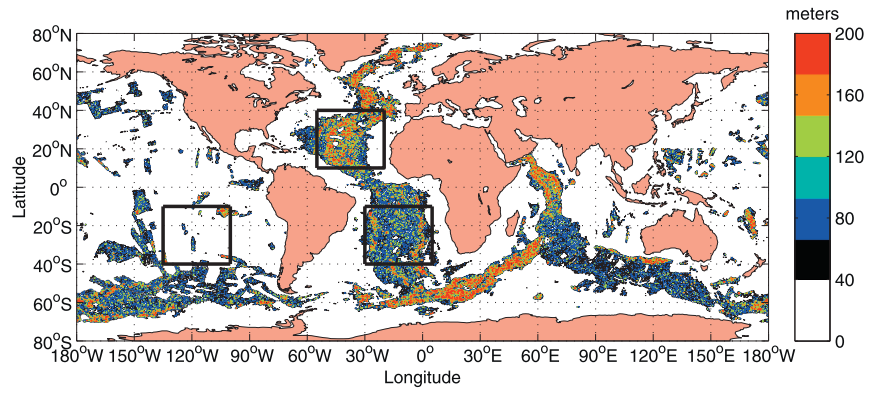

Fig. 4. Area weighted root mean square of the difference between model bathymetry with and without the abyssal hill roughness at $1 / 12.5^{\circ}$. The root mean square is calculated over a $1 / 4^{\circ} \times 1 / 4^{\circ}$ sub-grid. Contours are drawn from $40 \mathrm{~m}$ to $200 \mathrm{~m}$ at $40 \mathrm{~m}$ intervals. The boxed regions shown in the South Pacific, North Atlantic and South Atlantic oceans are used later to estimate internal wave response to changes in bottom roughness.

seconds. The model bathymetry with the added roughness, $D_{i j}^{S S G}$, is then interpolated using (1) with $\operatorname{SSG}\left(x_{i}, y_{j}\right)$ substituted for $\operatorname{SS}\left(x_{i}, y_{j}\right)$. Fig. 4 quantifies the impact of the added synthetic abyssal hill roughness by displaying the root mean square of the differences between the $1 / 12.5^{\circ}$ model grid with and without the synthetic roughness,

$R M S_{\text {bath }}=\sqrt{\sum_{i} \sum_{j}\left(D_{i j}^{S S G}-D_{i j}^{S S}\right)^{2} d A_{i j} / \sum_{i} \sum_{j} d A_{i j}}$.

$\mathrm{RMS}_{\text {bath }}$ is calculated by summing the squares of the bathymetric differences on the model grid over $1 / 4^{\circ} \times 1 / 4^{\circ}$ regions. The results for the $1 / 25^{\circ}$ model grid are qualitatively similar and are not shown for the sake of brevity. The global distribution of $\mathrm{RMS}_{\text {bath }}$ is very inhomogeneous, ranging from 0 to greater than $200 \mathrm{~m}$ depending on location. The white regions in Fig. 4 are regions in which there are no abyssal hills.

In Fig. 4 we also display 3 regions on which we will focus attention later in the paper. We focus on regions with large abyssal hills (the North Atlantic-NA-and South Atlantic-SA) and on regions with few and smaller abyssal hills (the South Pacific-SP). Each of the boxed regions is bounded by the same absolute values of latitude $\left(10^{\circ}-40^{\circ} \mathrm{N}, 10^{\circ}-40^{\circ} \mathrm{S}\right)$ and the same range in
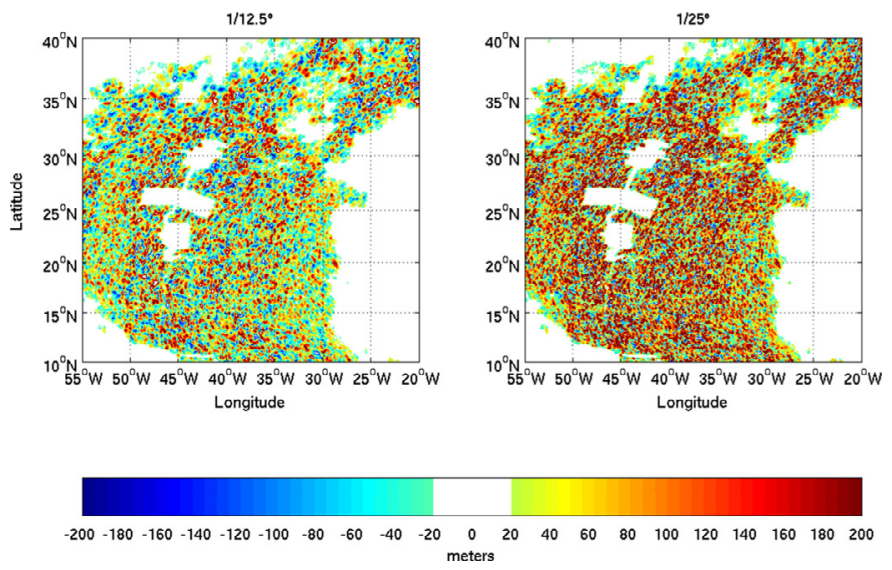

Fig. 5. Difference in model bathymetry, due to the addition of the synthetic abyssal hill roughness onto the $1 / 12.5^{\circ}$ and $1 / 25^{\circ}$ model grids, for the North Atlantic box shown in Fig. 4. The images show the differences $D^{S S G}-D^{S S}$ for model bathymetry with, $\mathrm{D}^{\mathrm{SSG}}$, and without, $\mathrm{D}^{\mathrm{SS}}$, the abyssal hill roughness. Contours are drawn at intervals of $20 \mathrm{~m}$ between -200 and $200 \mathrm{~m}$ depth. Differences between $-20 \mathrm{~m}$ and $20 \mathrm{~m}$ are shown in white.

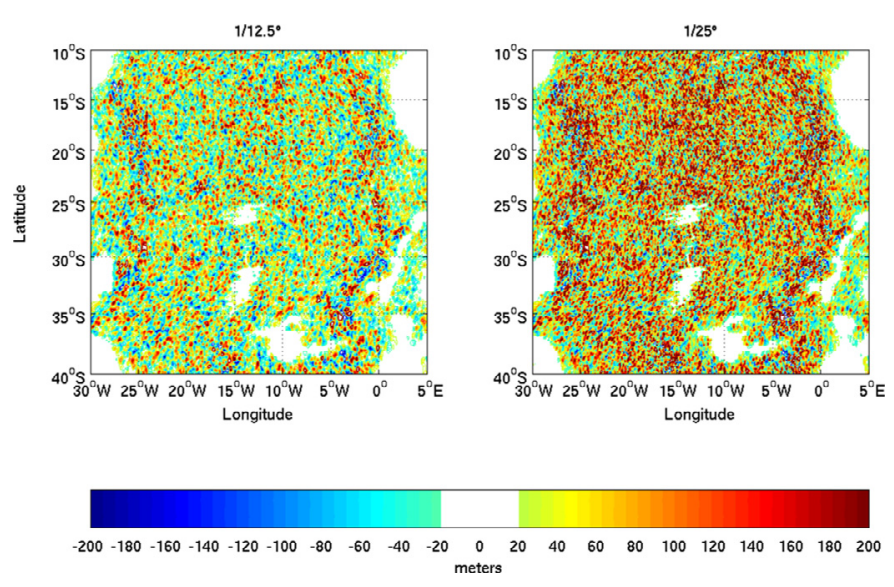

Fig. 6. Difference in model bathymetry As in Fig. 5 but for South Atlantic box shown in Fig. 4.

longitude and hence encloses equal surface areas. Furthermore, for a fixed grid resolution, each box contains equal numbers of model grid points. The internal tide impacts we are interested in measuring are not solely dependent on the changes in bottom roughness; they are also dependent on the bottom stratification and barotropic tides. The SP region enables us to monitor differences that may result from changes in model performance in the absence of abyssal hills.

Figs 5 and 6 respectively display the differences $D_{i j}^{S S G}-D_{i j}^{S S}$ between model bathymetries on the $1 / 12.5^{\circ}$ and $1 / 25^{\circ}$ grids within the boxed NA and SA regions depicted in Fig. 4. While the bathymetric differences at the two grid resolutions are qualitatively similar, it is evident that the higher resolution grid is able to provide much greater detail of the resolved abyssal hill structures. The white patches near the center of Fig. 5, the NA box, are regions where high-resolution acoustic soundings are available, such that no additional roughness from the statistical representation of the abyssal hill structures was added to the model bathymetry.

Tidal energy conversion is proportional to the topographic height, h, multiplied by the topographic gradient (e.g., Garner 2005; Nycander 2005). Motivated by these theoretical considerations, we respectively display, in Figs 7 and 8, the wavenumber spectra of the bathymetry and the bathymetric slopes. The figures display results for bathymetries with and without abyssal hill 

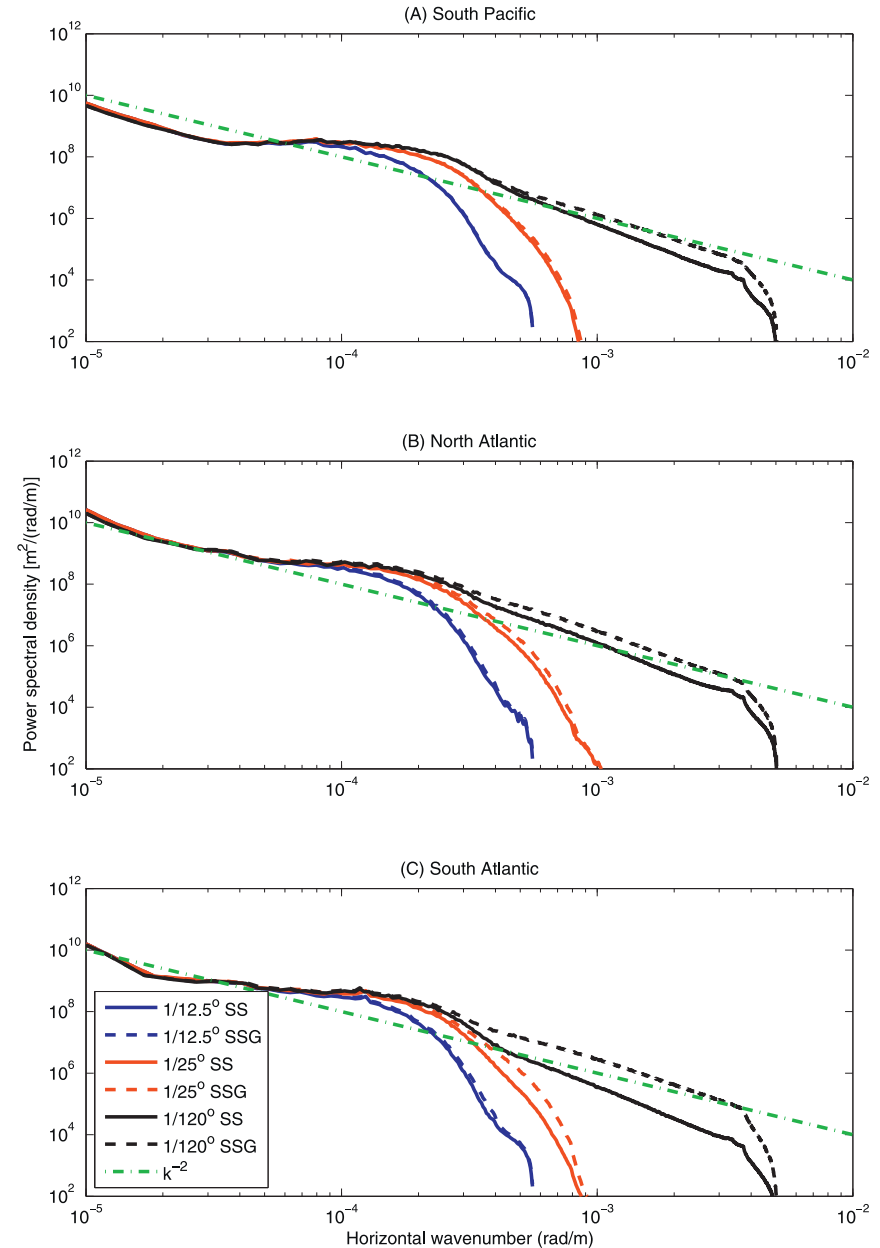

Fig. 7. Bathymetric wavenumber spectra for each of the three boxed regions depicted in Fig. 4. Each panel shows the power spectral density estimated from the model bathymetry with (SSG) and without (SS) the synthetic abyssal hill structure for the $1 / 12.5^{\circ}$ and $1 / 25^{\circ}$ model grids and for the $1 / 120^{\circ}$ bathymetry. The extra green dashed lines in each subplot represent a $\mathrm{k}^{-2}$ slope. (For interpretation of the references to colour in this figure legend, the reader is referred to the web version of this article.)

roughness (SSG vs. SS), for the three boxes (SP, NA, SA) shown in Fig. 4, and for grids with three different horizontal resolutionsthe $1 / 12.5^{\circ}$ and $1 / 25^{\circ}$ grids used in the numerical simulations presented in this paper, and the $1 / 120^{\circ}$ grid that was used to generate the $1 / 12.5^{\circ}$ and $1 / 25^{\circ}$ grids. The $1 / 120^{\circ}$ bathymetries were also discussed and used in Melet et al. (2013), who computed onedimensional bathymetric wavenumber spectra in the east-west direction from them. Here, the bathymetric spectra are computed over the model grid points in two dimensions, and are then reduced to one-dimensional spectra for display purposes. The spectra diverge due to either differences in grid resolution, or to the addition of synthetic roughness, at horizontal wavenumbers greater than or equal to about $10^{-4} \mathrm{rad} \mathrm{m} \mathrm{m}^{-1}$. The differences in spectral power on grids with versus without roughness is, not surprisingly, greatest on the $1 / 120^{\circ}$ grid. However, even on the $1 / 12.5^{\circ}$ and $1 / 25^{\circ}$ grids, the addition of the synthetic abyssal hill structure increases the power spectral density for wave numbers of $\mathrm{O}\left(4^{*} 10^{-4} \mathrm{rad} / \mathrm{m}\right)$ and higher (wavelengths of order $15 \mathrm{~km}$ and smaller), especially in the South Atlantic region, which as noted earlier is a region with large abyssal hills (Goff et al., 1997; see also Fig. 6 here).

We can anticipate the impacts of increasing grid resolution and added roughness on the internal tide activity in model results by
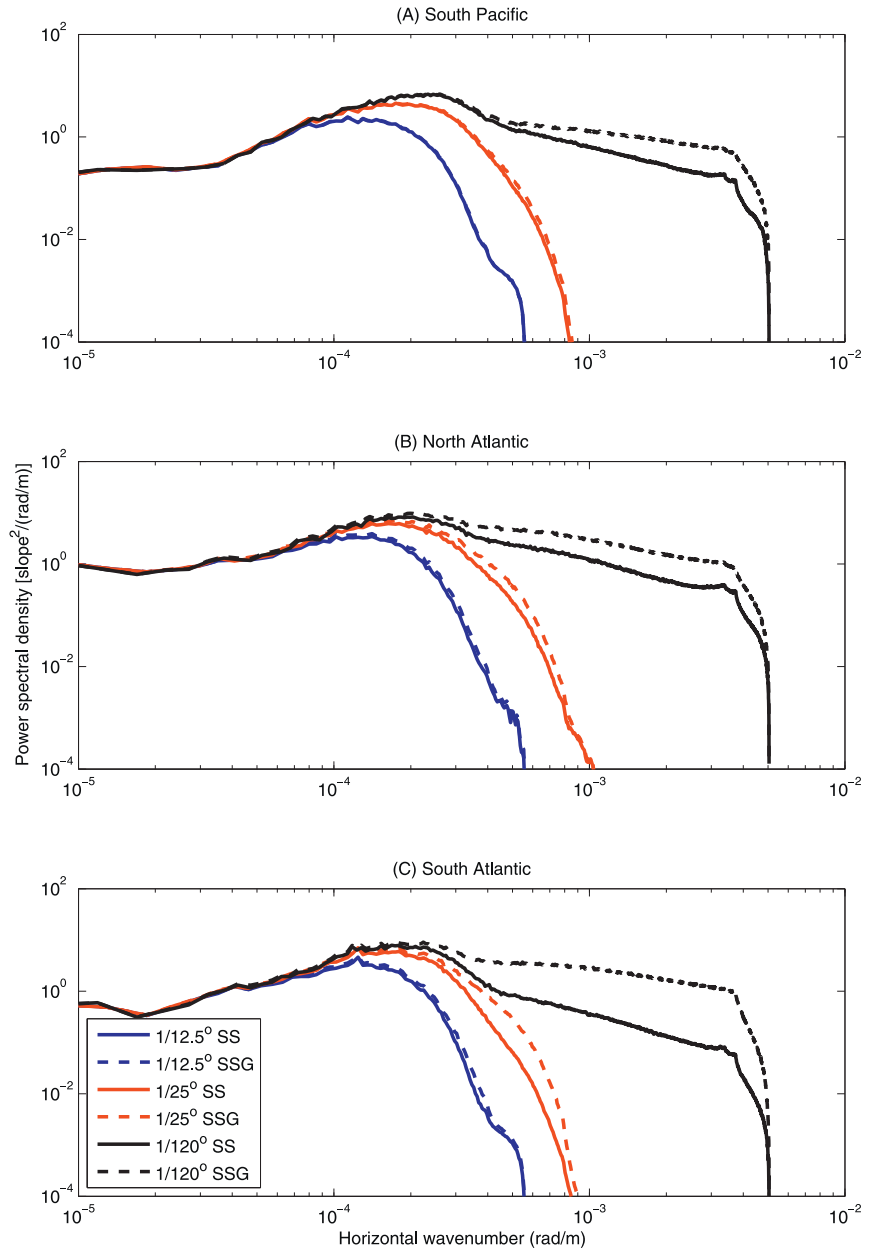

Fig. 8. Bathymetric slope wavenumber spectra for each of the three boxed regions depicted in Fig. 4. Each panel shows the power spectral density estimated from the model bathymetry with (SSG) and without (SS) the synthetic abyssal hill structure for the $1 / 12.5^{\circ}$ and $1 / 25^{\circ}$ model grids and for the $1 / 120^{\circ}$ bathymetry.

integrating the high-wavenumber portions of the spectra shown in Figs 7 and 8. The RMS topographic heights and RMS topographic slopes, integrated over wavenumbers greater than or equal to $10^{-4}$ rad $\mathrm{m}^{-1}$, are provided in Tables 1 and 2 . Table 1 indicates that RMS topographic heights on the SS grids (without additional synthetic roughness) increase by $98-113 \%$ and $35-40 \%$ when the resolution is increased from $1 / 12.5^{\circ}$ and $1 / 25^{\circ}$, respectively, to $1 / 120^{\circ}$ The addition of abyssal hills at a fixed resolution increases RMS topographic heights by $1-2 \%$ in the SP, by $5-8 \%$ in the NA and SA at model resolutions of $1 / 12.5^{\circ}$ and $1 / 25^{\circ}$, and by $10-$ $11 \%$ at $1 / 120^{\circ}$ RMS topographic slopes on the SS grids increase by $152-247 \%$ and $52-98 \%$ when the resolution is increased from $1 / 12.5^{\circ}$ and $1 / 25^{\circ}$, respectively, to $1 / 120^{\circ}$ (Table 2 ). When abyssal hills are added to the bathymetric data RMS topographic slope values increase by $1-2 \%$ in the SP, by $7-14 \%$ in the NA and SA at model resolutions of $1 / 12.5^{\circ}$ and $1 / 25^{\circ}$, and by $30-95 \%$ at $1 / 120^{\circ}$ At model resolutions of $1 / 12.5^{\circ}$ and $1 / 25^{\circ}$, the very small increase in RMS topographic heights and RMS topographic slopes cannot be expected to have much impact in the SP region. However, increases of $5-14 \%$ in the RMS values for the NA and SA cannot be considered negligible and therefore can be expected to produce a noticeable impact on the conversion of barotropic to baroclinic kinetic energy.

The spectra in Figs 7 and 8, and the results in Tables 1 and 2 , demonstrate that increasing horizontal resolution increases the 
Table 1

RMS topographic heights (m), computed over wavenumbers greater than or equal to $10^{-4} \mathrm{rad} / \mathrm{m}$ (wavelengths less than or equal to about $60 \mathrm{~km}$ ), from the spectra shown in Fig. 7. Integrals are performed with (SSG) and without (SS) abyssal hills, at $1 / 12.5^{\circ}, 1 / 25^{\circ}$, and $1 / 120^{\circ}$ horizontal resolution. Unbolded numbers in parentheses indicate percentage increase from SS to SSG, at fixed horizontal resolution. Bold numbers in parentheses indicate percentage increase from SS $1 / 12.5^{\circ}$ and $1 / 25^{\circ}$, respectively, to SS $1 / 120^{\circ}$, in other words, the percentage increase due to horizontal resolution, without the addition of abyssal hills.

\begin{tabular}{ll}
\hline South Pacific Region & High wavenumber RMS \\
Resolution & 107.91 \\
$1 / 12.5^{\circ}$ SS & $108.95(0.97 \%) \leftarrow$ Abyssal hill roughness \\
$1 / 12.5^{\circ}$ SSG & 167.61 \\
$1 / 25^{\circ}$ SS & $169.65(1.21 \%) \leftarrow$ Abyssal hill roughness \\
$1 / 25^{\circ}$ SSG & $230.47(\mathbf{1 1 3 . 5 7} \%$, 37.50\%) $\leftarrow$ Horizontal resolution \\
$1 / 120^{\circ}$ SS & $235.56(2.21 \%) \leftarrow$ Abyssal hill roughness \\
$1 / 120^{\circ}$ SSG & \\
North Atlantic Region & High wavenumber RMS \\
Resolution & 131.72 \\
$1 / 12.5^{\circ}$ SS & $140.36(6.56 \%) \leftarrow$ Abyssal hill roughness \\
$1 / 12.5^{\circ}$ SSG & 196.11 \\
$1 / 25^{\circ}$ SS & $211.68(7.94 \%) \leftarrow$ Abyssal hill roughness \\
$1 / 25^{\circ}$ SSG & $274.08(\mathbf{1 0 8 . 0 8} \%, \mathbf{3 9 . 7 6} \%) \leftarrow$ Horizontal resolution \\
$1 / 120^{\circ}$ SS & $300.66(9.70 \%) \leftarrow$ Abyssal hill roughness \\
$1 / 120^{\circ}$ SSG & \\
South Atlantic Region & High wavenumber RMS \\
Resolution & 131.19 \\
$1 / 12.5^{\circ}$ SS & $138.60(5.65 \%) \leftarrow$ Abyssal hill roughness \\
$1 / 12.5^{\circ}$ SSG & 191.77 \\
$1 / 25^{\circ}$ SS & $206.24(7.54 \%) \leftarrow$ Abyssal hill roughness \\
$1 / 25^{\circ}$ SSG & $260.09(\mathbf{9 8 . 2 5} \%, \mathbf{3 5 . 6 3} \%) \leftarrow$ Horizontal resolution \\
$1 / 120^{\circ}$ SS & $288.38(10.88 \%) \leftarrow$ Abyssal hill roughness \\
$1 / 120^{\circ}$ SSG & \\
\hline
\end{tabular}

Table 2

As in Table 1, but for RMS topographic slopes.

\begin{tabular}{ll}
\hline South Pacific Region & High wavenumber slope \\
Resolution & 0.0158 \\
$1 / 12.5^{\circ}$ SS & $0.0160(1.17 \%) \leftarrow$ Abyssal hill roughness \\
$1 / 12.5^{\circ}$ SSG & 0.0294 \\
$1 / 25^{\circ}$ SS & $0.0301(2.17 \%) \leftarrow$ Abyssal hill roughness \\
$1 / 25^{\circ}$ SSG & $0.0537(\mathbf{2 3 9 . 6 6 \% , ~ 8 2 . 6 6 \% )} \leftarrow$ Horizontal resolution \\
$1 / 120^{\circ}$ SS & $0.0696(29.62 \%) \leftarrow$ Abyssal hill roughness \\
$1 / 120^{\circ}$ SSG & \\
North Atlantic Region & High wavenumber slope \\
Resolution & 0.0190 \\
$1 / 12.5^{\circ}$ SS & $0.0204(7.58 \%) \leftarrow$ Abyssal hill roughness \\
$1 / 12.5^{\circ}$ SSG & 0.0332 \\
$1 / 25^{\circ}$ SS & $0.0373(12.21 \%) \leftarrow$ Abyssal hill roughness \\
$1 / 25^{\circ}$ SSG & $0.0658(\mathbf{2 4 6 . 6 0} \%, \mathbf{9 7 . 9 8} \%) \leftarrow$ Horizontal resolution \\
$1 / 120^{\circ}$ SS & $0.0949(44.10 \%) \leftarrow$ Abyssal hill roughness \\
$1 / 120^{\circ}$ SSG & \\
South Atlantic Region & High wavenumber slope \\
Resolution & 0.0187 \\
$1 / 12.5^{\circ}$ SS & $0.0200(6.89 \%) \leftarrow$ Abyssal hill roughness \\
$1 / 12.5^{\circ}$ SSG & 0.0311 \\
$1 / 25^{\circ}$ SS & $0.0354(13.75 \%) \leftarrow$ Abyssal hill roughness \\
$1 / 25^{\circ}$ SSG & $0.0472(\mathbf{1 5 2 . 3 1} \%, \mathbf{5 1 . 9 8 \% )} \leftarrow$ Horizontal resolution \\
$1 / 120^{\circ}$ SS & $0.0921(95.02 \%) \leftarrow$ Abyssal hill roughness \\
$1 / 120^{\circ}$ SSG & \\
\hline
\end{tabular}

small-scale roughness substantially, consistent with the results of Niwa and Hibiya (2011, 2014), even without the addition of the synthetic abyssal hill roughness. We therefore anticipate that increasing the resolution of small-scale features already in global bathymetric databases will yield enhanced internal tide activity, as in Niwa and Hibiya (2011, 2014). Based upon Figs 7 and 8, and Tables 1 and 2, we anticipate that the addition of synthetic abyssal hill roughness will yield further enhancements, especially as model resolution is increased, consistent with the linear analysis study of Melet et al. (2013). Furthermore, because of the greater spectral power at small scales with the addition of roughness, and be-

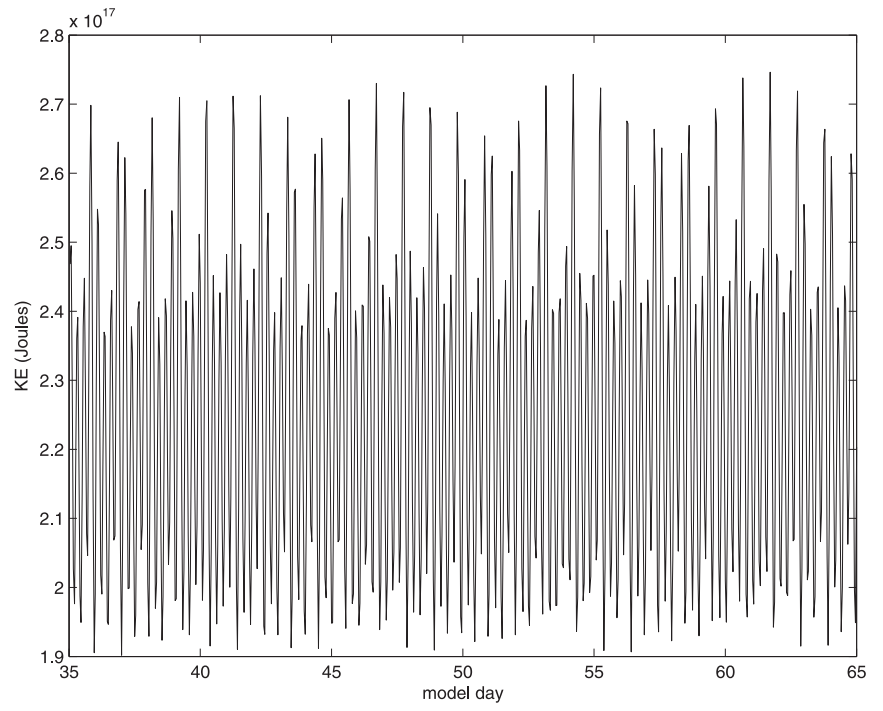

Fig. 9. Globally integrated barotropic kinetic energy vs. time, starting at model day 35 , for the $1 / 25^{\circ}$ resolution model simulation without abyssal hill roughness.

cause high vertical modes are excited by smaller horizontal scales in the topography (St. Laurent and Garrett, 2002), we anticipate more energy in the higher vertical modes when abyssal hill structures are included in our numerical simulations. Previous studies using HYCOM (e.g., Fig. 7 in Buijsman et al., 2016) indicate that the maximum conversion of barotropic to baroclinic kinetic energy in abyssal hill regions occurs in vertical mode 2 , consistent with the results of Zilberman et al. (2009). Finally, Fig. 7 also indicates that at the highest wavenumbers, the slope of the topographic power spectra is steeper than $\mathrm{k}^{-2}$ for all 3 resolutions shown on the figure $\left(1 / 12.5^{\circ}, 1 / 25^{\circ}\right.$, and $\left.1 / 120^{\circ}\right)$, indicating that numerical convergence would be achievable on all three grids as long as sufficient computing power were available (Zaron and Egbert 2006).

\subsection{Model spin-up}

The globally integrated barotropic kinetic energy, shown vs. time in Fig. 9 for the $1 / 25^{\circ}$ simulation without abyssal hill roughness, does not exhibit a noticeable trend after the 35-day spin-up period. Because internal waves travel more slowly than barotropic waves, the baroclinic kinetic energies take longer to spin up. In Figs 10 and 11 we display the $M_{2}$ and $K_{1}$ baroclinic kinetic energies, in vertical modes 1-4, averaged over 5-day windows, for the 3 boxed regions shown in Fig. 4. The $\mathrm{M}_{2}$ energies display a visible trend in the SP region for modes 1 and 2, but little trend in the NA and $S A$ regions. The $K_{1}$ energies display some trneds in all 3 regions. While the model appears not to have fully equilibrated, we will show in Section 5 that the difference in the baroclinic energy between simulations with and without abyssal hills appears to be relatively consistent over the 30 days used in our analysis. Furthermore, because $M_{2}$ has much more energy than $K_{1}$, we expect that $\mathrm{M}_{2}$ will dominate the results of interest here (increased energies and energy conversion rates with added roughness), and that the abyssal hill regions, which appear to be better equilibrated than non-abssyal hill regions (compare the NA and SA versus SP results in Figs 10 and 11), will also dominate the changes seen with the addition of abyssal hill roughness.

\section{Comparison with satellite altimetry-constrained models}

In this section we compare the modelled barotropic and lowmode baroclinic tides in our HYCOM simulations with tides 

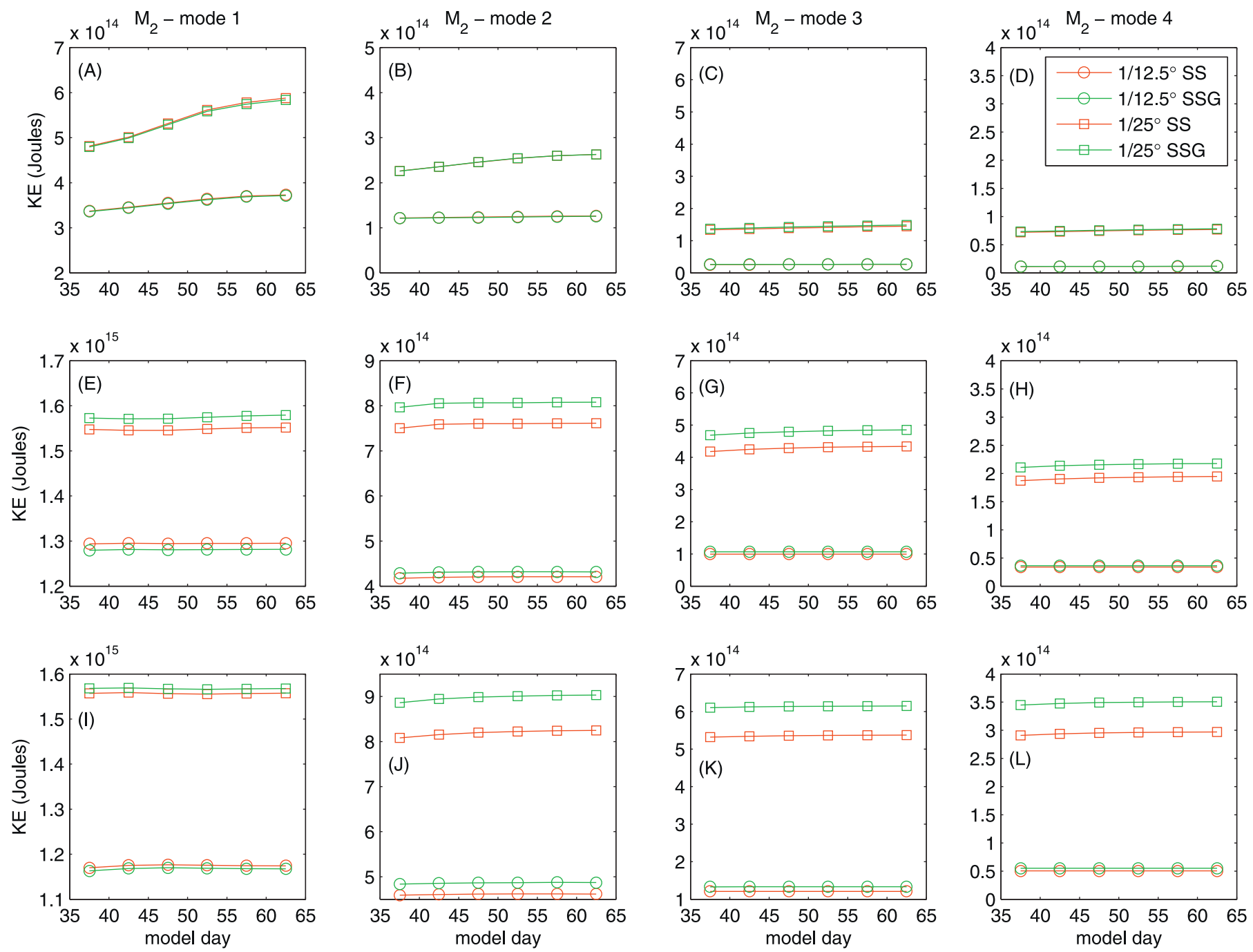

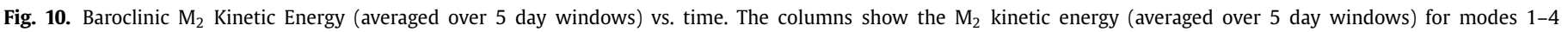

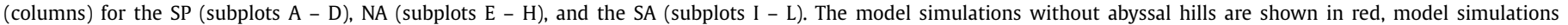

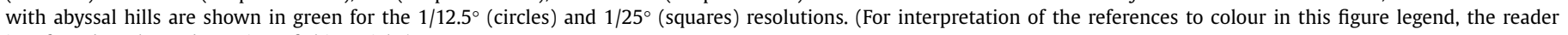
is referred to the web version of this article.)

derived from satellite altimetry-constrained tide models. The sea surface elevations, which are dominated by the large-scale barotropic tides, are compared to tidal elevations in the highly accurate satellite-altimetry constrained TPXO 7.2 barotropic tide model (Egbert et al., 1994; Egbert and Erofeeva, 2002). The HYCOM $\mathrm{M}_{2}$ and $\mathrm{K}_{1}$ elevation amplitudes and phases were interpolated onto the TPXO grid. The area-weighted root mean square (RMS) errors (e.g., Arbic et al., 2004; Stammer et al., 2014; among many) of the 4 HYCOM simulations with respect to TPXO were then calculated over the entire globe from those grid points with water column depth greater than $1000 \mathrm{~m}$, and are given in Table 3. The $M_{2}$ RMS elevation errors for the $1 / 12.5^{\circ}$ simulations without and with the synthetic roughness are very similar (7.00 and $6.89 \mathrm{~cm}$, respectively). Likewise, the $\mathrm{K}_{1}$ errors in the two $1 / 12.5^{\circ}$ simulations are little affected by the addition of the roughness. Table 3 also indicates that the addition of roughness does not impact the RMS elevation errors in the $1 / 25^{\circ}$ simulations. Furthermore, the increase in resolution from $1 / 12.5^{\circ}$ to $1 / 25^{\circ}$ does not greatly impact the errors. However, we remind the reader that the parameterized topographic wave drag was not re-tuned for the higher resolution; this likely impacts the $1 / 25^{\circ}$ simulation errors. All of the elevation errors displayed in Table 3 are comparable to those seen in other simulations of forward (non-data-assimilative) tide models (e.g., Arbic et al., 2004; Stammer et al., 2014, and others).

Next we compare the modelled globally integrated barotropic tidal kinetic energies within the HYCOM simulations, and with the tidal kinetic energies in TPXO. As shown in Table 4, roughness does not strongly impact the modeled barotropic kinetic energies, just as it did not strongly impact the large-scale sea surface elevations. The barotropic tidal kinetic energy decreases by approximately $10 \%$ during model execution at $1 / 25^{\circ}$ compared to model execution at $1 / 12.5^{\circ}$. This decrease of barotropic kinetic energy with increased horizontal resolution, though somewhat counter intuitive, is consistent with results of other studies (Egbert et al., 2004). The combined $\mathrm{M}_{2}$ and $\mathrm{K}_{1}$ kinetic energies in our $1 / 12.5^{\circ}$ simulations are $\sim 20 \%$ larger than the combined $\mathrm{M}_{2}$ and $\mathrm{K}_{1}$ barotropic kinetic energies in TPXO, while our $1 / 25^{\circ}$ simulation is $\sim 10 \%$ more energetic than TPXO.

Finally, we compare the sea surface elevation signatures of the modelled internal tides with the signatures seen in along-track satellite altimetry. Following the work of Shriver et al. (2012) and Ansong et al. (2015) the model output is interpolated to the 1dimensional altimeter tracks and the amplitude of the HYCOM $\mathrm{M}_{2}$ internal tide sea surface height signature is estimated by bandpassing the $\mathrm{M}_{2}$ surface elevation amplitudes to permit wavelengths 

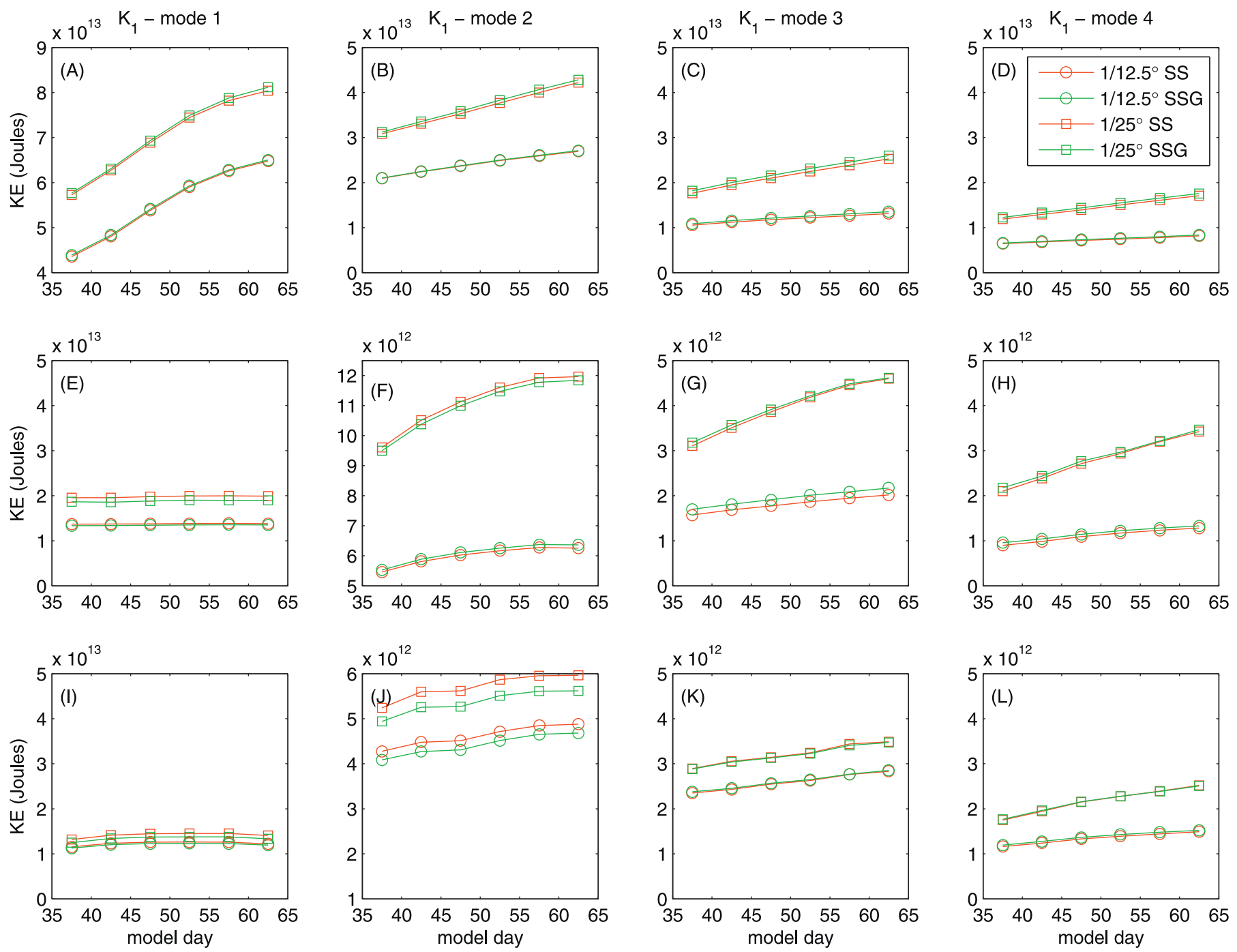

Fig. 11. As in Fig. 10 but for $K_{1}$.

Table 3

Global Root Mean Square Error (RMSE) of modelled tidal sea surface heights with respect to TPXO7.2, computed over water depths exceeding $1000 \mathrm{~m}$. SS represents model without the added abyssal hill roughness, while SSG represents models with abyssal hill roughness.

\begin{tabular}{|c|c|c|c|c|}
\hline \multirow{3}{*}{ Model } & \multicolumn{4}{|c|}{ Sea surface height RMSE $(\mathrm{cm})$} \\
\hline & \multicolumn{2}{|c|}{$1 / 12.5^{\circ}$} & \multicolumn{2}{|c|}{$1 / 25^{\circ}$} \\
\hline & SS & SSG & SS & SSG \\
\hline \multicolumn{5}{|c|}{ Constituent } \\
\hline $\mathbf{M}_{2}$ & 7.00 & 6.89 & 7.29 & 7.47 \\
\hline $\mathbf{K}_{1}$ & 2.95 & 2.93 & 2.83 & 2.80 \\
\hline
\end{tabular}

in the 50-400 km range. Internal tide amplitudes are also computed from application of the same technique to tidal elevation amplitude maps estimated from along-track satellite altimetry data (Ray and Mitchum, 1996; Ray and Byrne, 2010). Maps of internal tide amplitudes computed from our simulations and from alongtrack altimetry are shown in Fig. 12. The internal tide amplitudes in the simulations are comparable to those seen in along-track altimetry. However, large amplitude internal tides are seen over a greater area in the simulations, especially in the $1 / 25^{\circ}$ simulations, than in altimetry. As discussed at length in Ansong et al. (2015), internal tide amplitudes are greatly affected by the strength of to-
Table 4

Global Barotropic Tidal Kinetic Energies $\left(10^{15} \mathrm{~J}\right)$ for each of the model simulations with (SSG) and without (SS) abyssal hill roughness at $1 / 12.5^{\circ}$ and $1 / 25^{\circ}$ resolution and from TPXO (Egbert and Ray, 2003).

\begin{tabular}{llll}
\hline & $\mathrm{M}_{2}$ & $\mathrm{~K}_{1}$ & Total \\
\hline $1 / 12^{\circ}$ SS & 223 & 24 & 247 \\
$1 / 12^{\circ}$ SSG & 221 & 24 & 246 \\
$1 / 25^{\circ}$ SS & 202 & 23 & 225 \\
$1 / 25^{\circ}$ SSG & 204 & 23 & 227 \\
TPXO & 169 & 34 & 204 \\
\hline
\end{tabular}

pographic wave drag. The wave drag employed here was tuned for barotropic tides at $1 / 12.5^{\circ}$ resolution, not for baroclinic tides. In addition, the internal tides in the simulations shown here do not experience scattering by mesoscale eddies, unlike tides in the simulations of Ansong et al. (2015), who employed both atmospheric and tidal forcing, and unlike tides in the actual ocean. The lack of wave drag tuning, and of scattering by mesoscale eddies, may help to explain why the internal tide amplitudes in the simulations shown here are somewhat larger than those in altimetry, as is also seen in Table 5, which displays amplitudes averaged spatially over the globe and over the 5 "hotspot regions" of strong internal tide activity shown in Fig. 12b. The area-averaged amplitudes in Table 5 are computed for depths greater than $1500 \mathrm{~m}$. For 

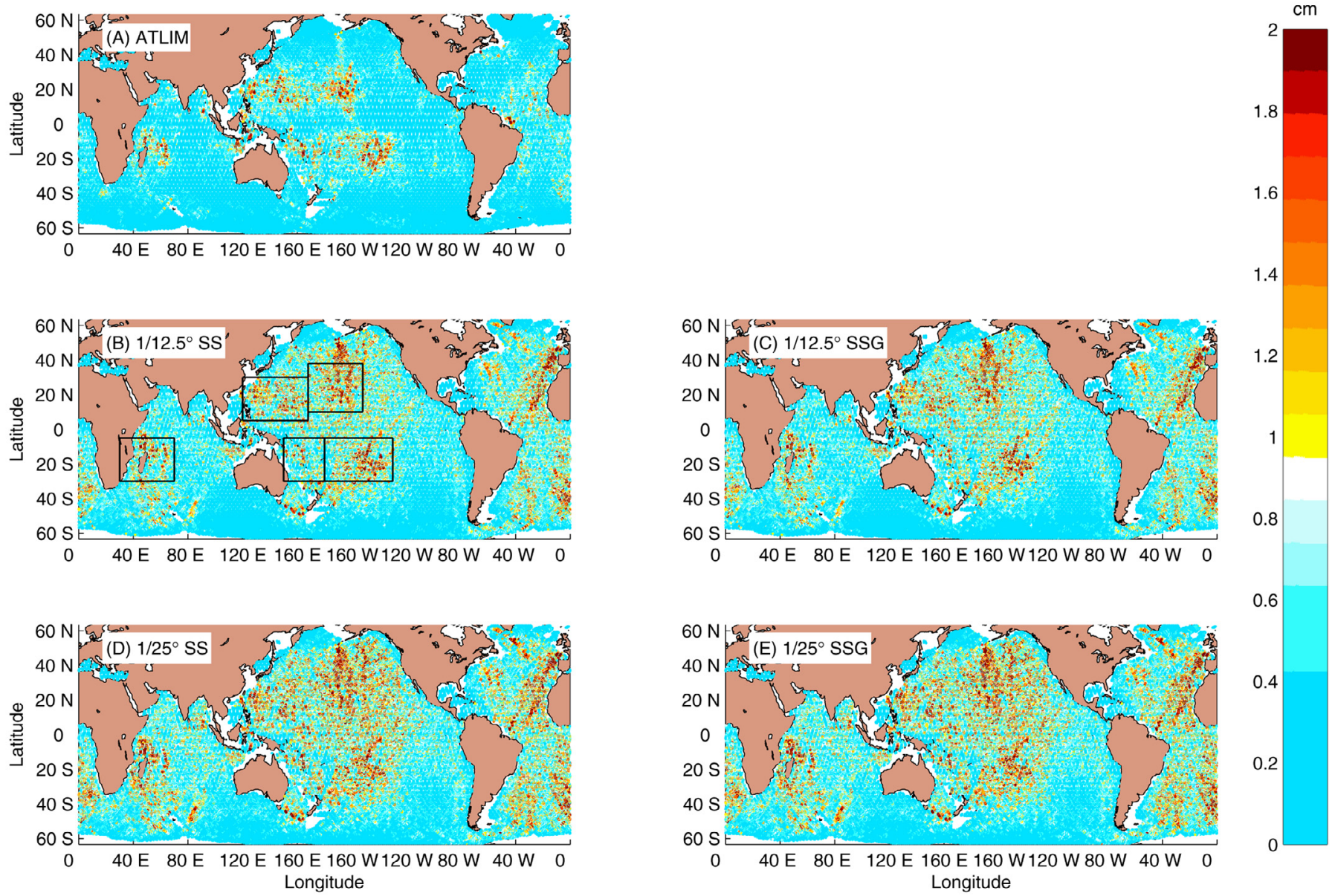

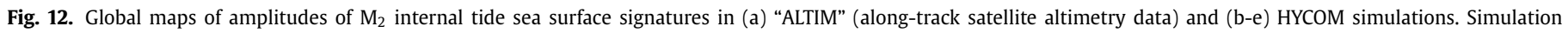
labels are in the upper-left corner, over Asia.

Table 5

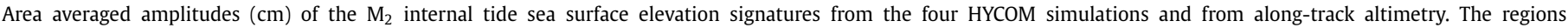
correspond to those used by Shriver et al. (2012) and Ansong et al. (2015) and are shown in Fig. 12b. All computations are for depths deeper than 1500 m.

\begin{tabular}{|c|c|c|c|c|c|c|c|}
\hline & Global & Hawaii & $\begin{array}{l}\text { East of } \\
\text { Phillipines }\end{array}$ & $\begin{array}{l}\text { Tropical } \\
\text { South Pacific }\end{array}$ & $\begin{array}{l}\text { Tropical } \\
\text { SW Pacific }\end{array}$ & Madagascar & $\begin{array}{l}\text { Rest of } \\
\text { world ocean }\end{array}$ \\
\hline altimeter & 0.468 & 0.817 & 0.829 & 0.857 & 0.758 & 0.728 & 0.375 \\
\hline $1 / 12.5^{\circ} \mathrm{SS}$ & 0.715 & 1.076 & 0.969 & 1.014 & 0.806 & 0.943 & 0.655 \\
\hline $1 / 12.5^{\circ} \mathrm{SSG}$ & 0.715 & 1.076 & 0.967 & 1.015 & 0.806 & 0.949 & 0.655 \\
\hline $1 / 25^{\circ} \mathrm{SS}$ & 0.808 & 1.179 & 1.047 & 1.039 & 0.877 & 1.056 & 0.754 \\
\hline $1 / 25^{\circ} \mathrm{SSG}$ & 0.809 & 1.179 & 1.042 & 1.055 & 0.874 & 1.054 & 0.755 \\
\hline
\end{tabular}

simplicity, in the case of the altimeter values, the topography of the $1 / 12.5^{\circ}$ resolution (without additional roughness) was used as a reference bathymetry for the calculations. As with the sea surface elevation errors, the addition of abyssal hills does not greatly impact the spatially averaged internal tide sea surface heights, which largely reflect the first baroclinic mode.

\section{Roughness impacts on energy conversion rates and modal energy partitions}

In this section we quantify the impact of the small-scale abyssal hill roughness on the internal tide fields. We focus on the conversion rate of barotropic to baroclinic tidal energy, and on the vertical modal structure of the simulated baroclinic tidal field. We also examine how the addition of abyssal hills impacts the barotropic tide, apparently resulting from the conversion of baroclinic tidal energy back into barotropic tidal energy.
Table 6

Net $\mathrm{M}_{2}$ plus $\mathrm{K}_{1}$ barotropic to baroclinic energy conversion rates (Watts) calculated for the global integral and for each of the boxed regions shown in Fig. 4: South Pacific (SP), North Atlantic (NA), and South Atlantic (SA).

\begin{tabular}{|c|c|c|c|c|c|}
\hline \multicolumn{6}{|c|}{ Net conversion rate of barotropic to baroclinic energy (Watts) } \\
\hline Model & & Global & SP & NA & SA \\
\hline \multirow[t]{2}{*}{$1 / 12.5^{\circ}$} & SS & $5.33 E+11$ & $3.37 \mathrm{E}+09$ & $1.31 \mathrm{E}+10$ & $1.44 \mathrm{E}+10$ \\
\hline & SSG & $5.39 \mathrm{E}+11$ & $3.35 \mathrm{E}+09$ & $1.35 \mathrm{E}+10$ & $1.52 \mathrm{E}+10$ \\
\hline \multirow[t]{2}{*}{$1 / 25^{\circ}$} & SS & $7.61 \mathrm{E}+11$ & $6.35 \mathrm{E}+09$ & $1.72 \mathrm{E}+10$ & $2.54 \mathrm{E}+10$ \\
\hline & SSG & $7.87 \mathrm{E}+11$ & $6.42 \mathrm{E}+10$ & $1.91 \mathrm{E}+10$ & $2.94 \mathrm{E}+10$ \\
\hline
\end{tabular}

\subsection{Tidal energy conversion}

We begin with the globally integrated barotropic to baroclinic energy conversion rates, which are listed for the four simulations in Table 6 . At $1 / 12.5^{\circ}$ resolution the global conversion rates are 533 

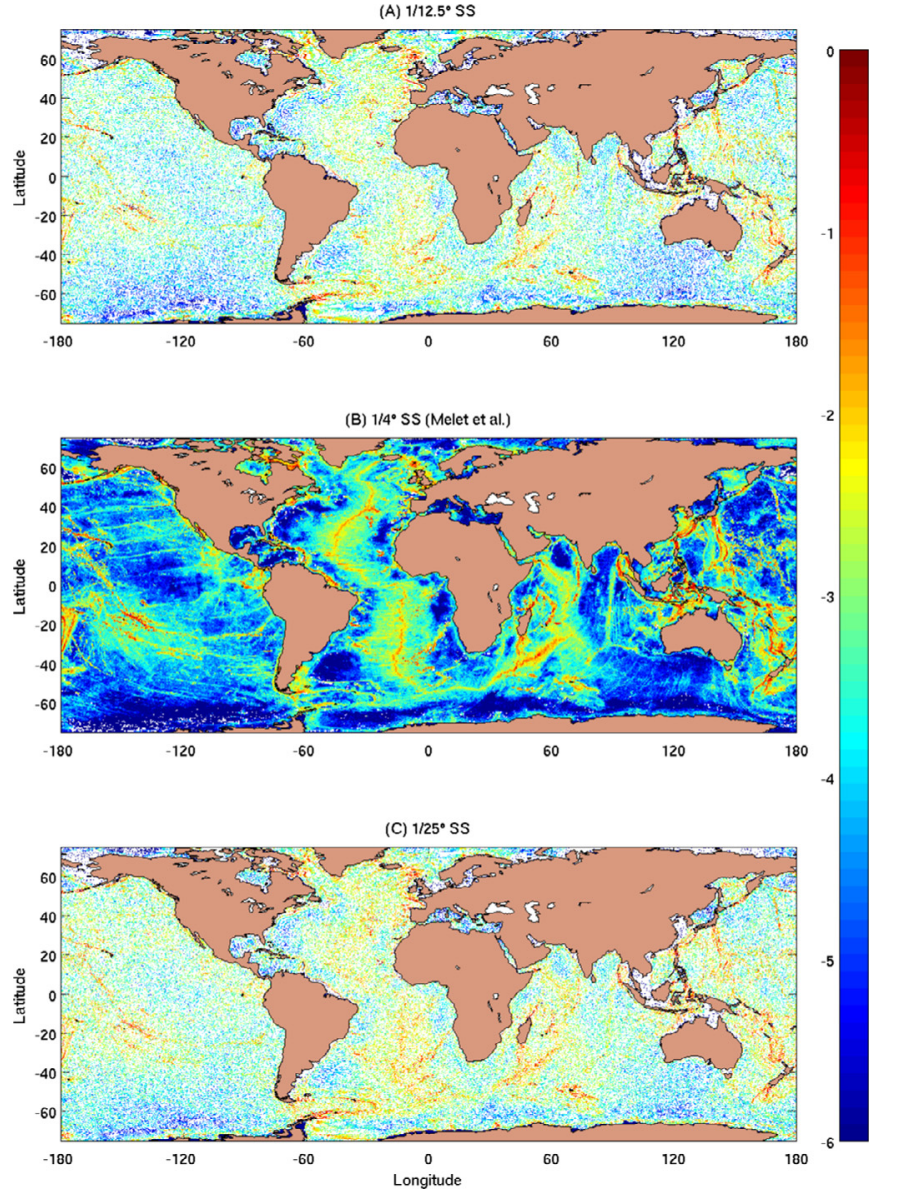

Fig. 13. Barotropic to baroclinic conversion rates, in $\log _{10}\left(\mathrm{~mW} \mathrm{~m}^{-2}\right)$, in the $1 / 12.5^{\circ}$ (top) and $1 / 25^{\circ}$ (bottom) simulations without added synthetic roughness alongside the net barotropic to baroclinic conversion rates at $1 / 4^{\circ}$ (center) from Melet et al., (2013).

and 539 GW, respectively, for simulations without and with roughness. The $1 / 12.5^{\circ}$ conversion rates are comparable to but lower than the conversion rates estimated from other global models (see, for instance, Table 3 in Simmons et al., 2004). At $1 / 25^{\circ}$ resolution the global conversion rates are 761 and $787 \mathrm{GW}$ for the without and with roughness simulations. The $1 / 25^{\circ}$ conversion rates are within the range of global conversion rates found in Simmons et al. (2004), and are also comparable to the rates computed by Niwa and Hibiya (2014), despite several important technical differences between our simulations and the Niwa and Hibiya simulations. For instance, whereas our simulations employ a parameterized topographic wave drag, Niwa and Hibiya (2014) employed a linear drag on the depth varying components of the horizontal velocities. Niwa and Hibiya (2014) also employed a horizontally varying stratification, whereas our stratification is horizontally uniform. The total of the $M_{2}$ and $K_{1}$ baroclinic conversion rates reported by Niwa and Hibiya (2014) was 635 (756) GW at 1/12 ${ }^{\circ}\left(1 / 20^{\circ}\right)$. Fig. 13 shows maps of conversion rates for our $1 / 12.5^{\circ}$ and $1 / 25^{\circ}$ simulations, without added synthetic roughness, respectively, alongside the map of conversion rates estimated by Melet et al., (2013). The three conversion maps shown in Fig. 13 are very similar to previous maps of conversion rates (e.g., Fig. 12 in Simmons et al., 2004; Fig. 3 in Niwa and Hibiya, 2011; and Fig. 2 in Niwa and Hibiya, 2014), emphasizing areas of rough topography such as mid-ocean ridges and seamount chains. The conversion rates at $1 / 25^{\circ}$ resolution are noticeably higher than at $1 / 12.5^{\circ}$ resolution, consistent with the results of Niwa and Hibiya (2014) and others.
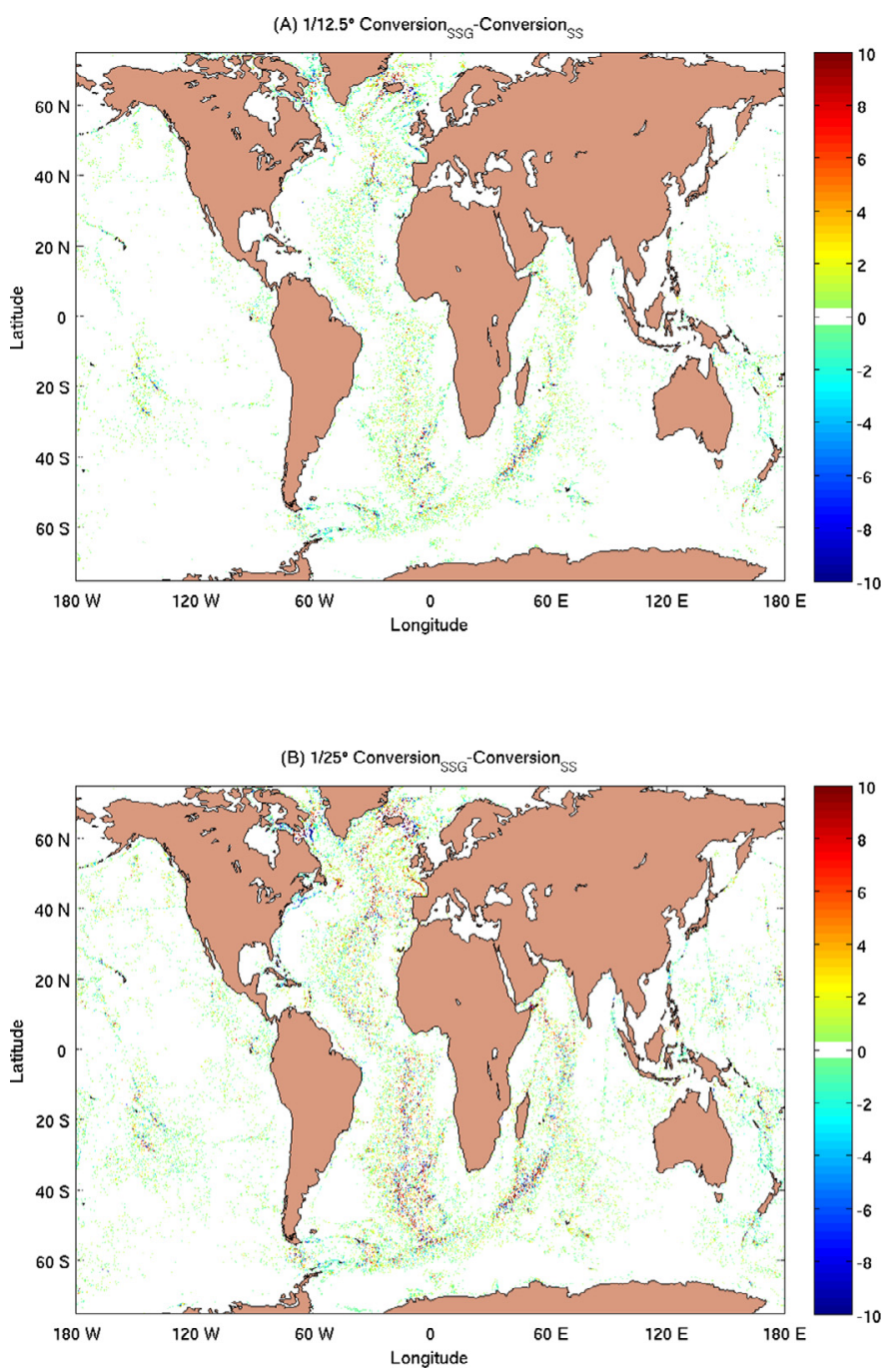

Fig. 14. The difference in the conversion rates of barotropic to baroclinic kinetic energy $\left(\mathrm{mW} \mathrm{m}^{-2}\right)$ with minus without the added synthetic roughness at $1 / 12.5^{\circ}$ and $1 / 25^{\circ}$ resolution.

In our $1 / 12.5^{\circ}\left(1 / 25^{\circ}\right)$ simulations we see an increase in the global conversion rate of $1.2 \%(3.4 \%)$ when the model is run with the additional abyssal hill roughness (Table 6). Maps of the differences between the conversion rates for the simulations with and without abyssal hills are shown in Fig. 14 for the two model resolutions. The areas of increased conversion seen in Fig. 14 are associated with the areas of increased roughness seen in Fig. 4. The abyssal hills have a much greater impact at $1 / 25^{\circ}$ than at $1 / 12.5^{\circ}$ horizontal resolution (Fig. 14). This is due to the fact that with a characteristic length scale of $2-10 \mathrm{~km}$, the abyssal hill structures are better resolved in the higher horizontal resolution simulations. The greater impact of the roughness on conversion rates in the $1 / 25^{\circ}$ simulations than in the $1 / 12.5^{\circ}$ simulations is consistent with the greater impact of the roughness on the bathymetric spectra on the higher resolution grid (Figs 7 and 8; Tables 1 and 2).

The $1.2 \%(3.4 \%)$ increases in global energy conversion rates in our $1 / 12.5^{\circ}\left(1 / 25^{\circ}\right)$ simulations performed with the addition of abyssal hills can be compared with the $10 \%$ increase in global conversion that Melet et al. (2013) found with the addition of abyssal hills into a linear analysis study, done both with and without a correction for supercriticality. In the region of the Mid-Atlantic Ridge located in the South Atlantic and bounded by $32^{\circ} \mathrm{S}$ to $22^{\circ} \mathrm{S}$ and $8^{\circ}$ $\mathrm{W}$ and $20^{\circ} \mathrm{W}$, Melet et al. (2013) estimated an increase of $89 \%$ (or 

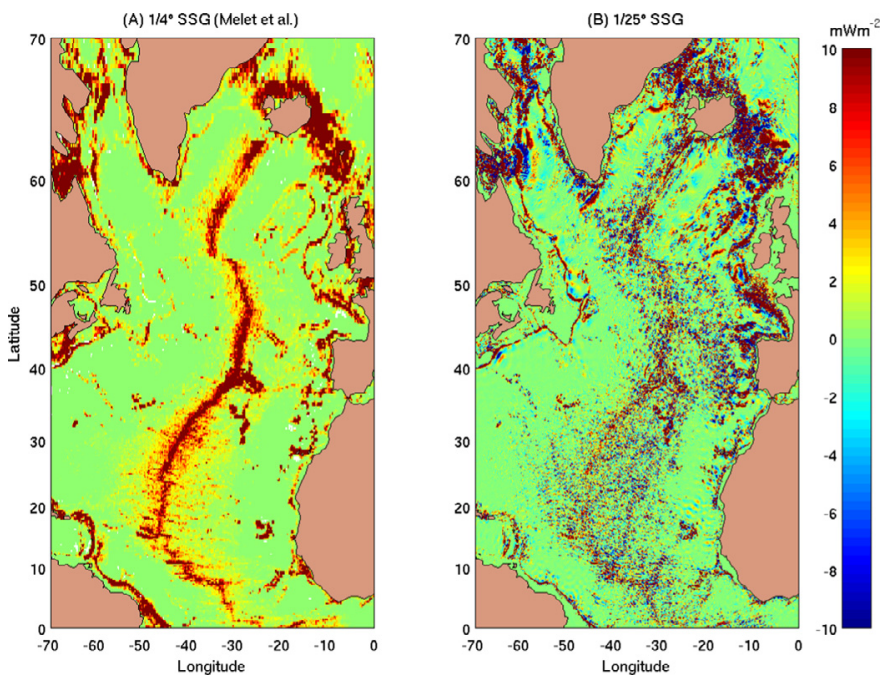

Fig. 15. Conversion rates within the North Atlantic. Left panel shows the conversion rates estimated using linear theory averaged over $1 / 4^{\circ}$ (Melet et al., 2013). The right panel shows the conversion rates from the $1 / 25^{\circ}$ simulation with abyssal hills (SSG).

$64 \%$ when empirically corrected for supercritical slopes) in the $\mathrm{M}_{2}$ energy flux into internal tides due to the inclusion of abyssal hills. In the same region, in our numerical simulations with synthetic abyssal hills included, we find a more modest increase in the combined $\mathrm{M}_{2}$ and $\mathrm{K}_{1}$ energy flux into internal tides of $17 \%(31 \%)$ at $1 / 12.5^{\circ}\left(1 / 25^{\circ}\right)$ resolution. The more modest increase seen in our numerical results is likely due to the limitations imposed by finite horizontal and vertical resolution in a numerical model. On the other hand, an advantage of the numerical simulations used in this paper is that they do not require a correction for supercritical slopes. Table 6 indicates that the SP region experiences little difference in conversion rates with the inclusion of abyssal hills, consistent with the fact that the SP region does not contain large numbers of abyssal hills (Fig. 4). The SA and NA regions see a greater increase (up to $16 \%$ ), especially in the $1 / 25^{\circ}$ simulations, in tidal energy conversion with the addition of abyssal hills. Going beyond quantitative comparisons, we note a strong visual similarity between the map of the difference in energy conversion rates with the addition of abyssal hills in our $1 / 25^{\circ}$ numerical simulations (Fig. 14) and in the linear analysis study of Melet et al. (2013; their Fig. 8b), especially in the Atlantic and Indian Oceans. This visual similarity again suggests to us that our numerical models are simulating the correct spatial geography of abyssal hill-mediated internal tide conversion, even if the amplitudes are still somewhat limited by the resolution of the numerical simulations. Finally, we point out again that, as was anticipated from the bathymetric spectra, the impact of abyssal hills on tidal energy conversion, though measureable, is on top of the larger impact of increasing model resolution.

The HYCOM simulations also exhibit greater negative conversion (the conversion of baroclinic kinetic energy to barotropic kinetic energy) as seen in Fig. 15 which displays maps of the conversion rates for the North Atlantic for the $1 / 25^{\circ}$ simulation with abyssal hills next to the Melet et al. (2013) conversion rate. The impact on the barotropic SSH, zonal velocities, and meridional velocities resulting from the addition of abyssal hills is shown in Fig. 16. The largest differences occur in the Atlantic, where the differences in the conversion of barotropic kinetic energy to baroclinic kinetic energy with the addition of abyssal hills are also greatest. The differences between the barotropic $M_{2}$ sea surface amplitudes in the North Atlantic are as large as $10 \mathrm{~cm}$ in $1 / 25^{\circ}$ simulations. Such differences are as much as five times larger than, and are opposite
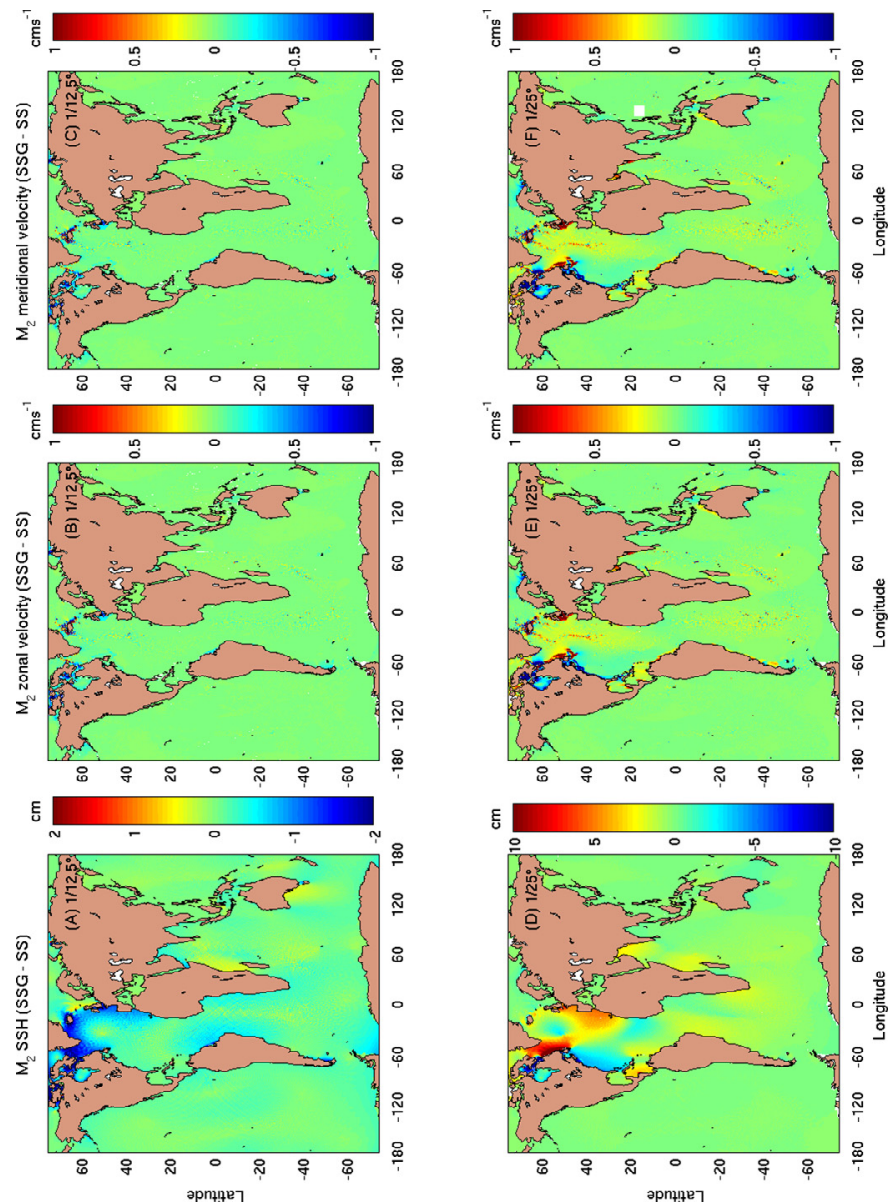

Fig. 16. Difference in the amplitudes of the barotropic sea surface height ( $\mathrm{m}$ ) and barotropic velocity fields $\left(\mathrm{ms}^{-1}\right)$, with the addition of abyssal hill roughness, at $1 / 12.5^{\circ}$ (left column) and $1 / 25^{\circ}$ (right column) resolution.

in sign to, those in the $1 / 12.5^{\circ}$ simulations. The differences in the zonal and meridional velocity fields are also much greater than, and opposite in sign to, those in the $1 / 25^{\circ}$ simulations compared to the $1 / 12.5^{\circ}$ simulations, as seen most noticeably in the English Channel, Celtic, and Irish Seas and also along the coast of Newfoundland and Labrador. The best explanation for the differences in the barotropic tide between the simulations with and without abyssal hills is that the numerical simulations allow for feedback of the baroclinic tide to impact the barotropic tide. This effect is not accounted for in the linear theory of Melet et al. (2013). Further explanation of this effect, and its strong dependence on model resolution, awaits further study.

\subsection{Modal partition of baroclinic tidal energy}

We next turn to the impact of the abyssal hills on the partition of baroclinic tidal energy amongst the vertical modes, focusing on the 3 regions displayed in Fig. 4 . The horizontal velocity fields $(u, v)$ and vertical displacement, $\hat{\eta}$, may be represented by their projection onto the vertical modes:

$$
u=\sum_{n=1}^{\infty} a_{n} F_{n}, \quad v=\sum_{n=1}^{\infty} b_{n} F_{n}, \quad \hat{\eta}=\sum_{n=1}^{\infty} p_{n} W_{n},
$$

where $a_{n}=\frac{1}{H} \int_{-H}^{0} u F_{n} d z$ and $b_{n}=\frac{1}{H} \int_{-H}^{0} v F_{n} d z$ are the projection coefficients of the horizontal velocity fields, and $p_{n}=$ $\frac{1}{H} \int_{-H}^{0}\left(\frac{N^{2}(z)-\sigma^{2}}{\sigma^{2}-f^{2}}\right) \hat{\eta} W_{n} d z$ is the projection of the vertical displacements, $\hat{\eta}$, onto the appropriate eigenfunctions, where $\sigma$ is the tidal frequency and $f$ is the Coriolis parameter. The eigenfunctions were 

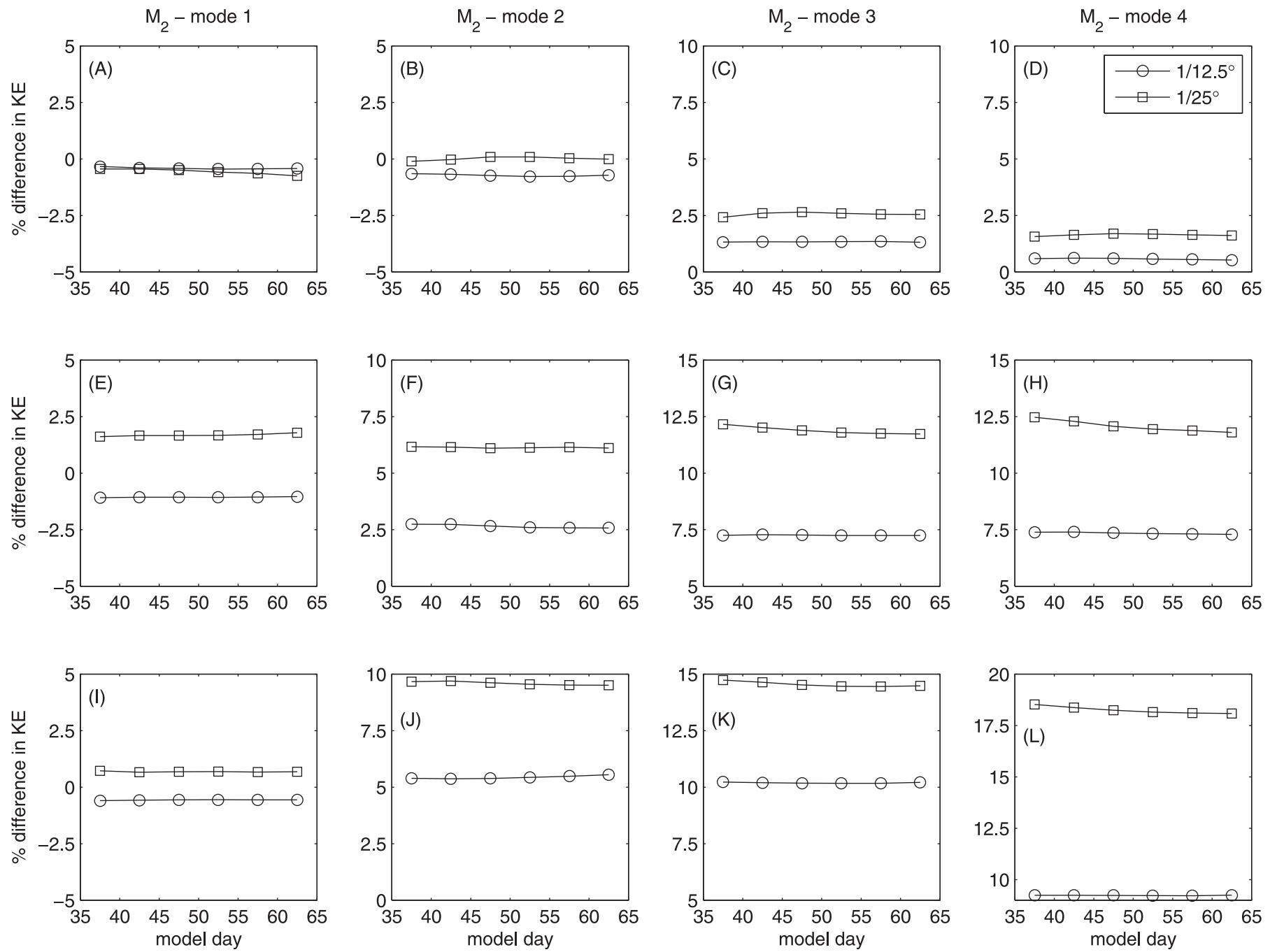

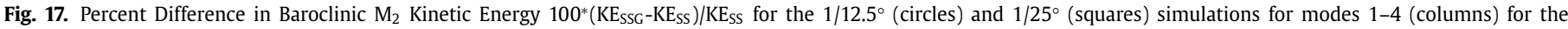
SP (subplots A - D), NA (subplots E - H), and the SA (subplots I - L).

calculated using the WOCE $N^{2}(\mathrm{z})$ profile in Fig. 1 applied at $30^{\circ}$ $\mathrm{S}, 135^{\circ} \mathrm{W}$ with bottom depth $4100 \mathrm{~m}$ and $50 \mathrm{~m}$ intervals in the vertical. The horizontal wavelengths for the first four modes are approximately $146,75,52$, and $40 \mathrm{~km}$. Applying the rule-of-thumb that eight points per wavelength are required to resolve a wave, we see that vertical mode 4 is near the upper limit of what our $1 / 25^{\circ}$ simulation can resolve.

The baroclinic zonal velocities $u$ and meridional velocities $v$ at every horizontal grid point in each of the 3 boxed regions shown in Fig. 4 are interpolated from their native isopycnal space to $50 \mathrm{~m}$ depth intervals, and are then projected onto the 4 vertical modes. The projection coefficients $a_{n}$ and $b_{n}$ are then processed using harmonic tidal analysis to estimate the modal partition of $\mathrm{M}_{2}$ and $\mathrm{K}_{1}$ kinetic energy. Figs 17 and 18 show the percentage changes in modal KE values, averaged over the boxes and over 5 day windows, due to the addition of small-scale roughness for constituents $M_{2}$ and $K_{1}$, respectively. Although the model has not fully achieved equilibrium (Figs 10 and 11) the percent difference between the model simulations with and without abyssal hills is very consistent over the duration of the simulations. With the exception of modes 3 and 4 for constituent $K_{1}$ which vary by up to $3 \%$, the typical range for percent difference is no more than $0.5 \%$ for the 4 modes in the 3 regions. The addition of the synthetic abyssal hill structure generally results in small changes in the amount of $\mathrm{KE}$ in the first mode and an increase in higher mode $\mathrm{KE}$, by up to $18 \%$, especially in the $1 / 25^{\circ}$ simulations and especially in the regions with larger abyssal hills (NA and SA). The changes seen in $\mathrm{M}_{2}$ are generally larger than the changes in $K_{1}$. Changes in KE for constituent $K_{1}$ are typically less than $5 \%$ with the exception of an increase for modes 3 and 4 in the NA at $1 / 12.5^{\circ}$ of $6-8 \% K_{1} \mathrm{KE}$ in modes 1 and 2 decrease by up to $6 \%$ in the NA and SA. The smaller changes in $K_{1}$ KE are consistent with the findings of Niwa and Hibiya (2011) who showed that conversion of $K_{1} \mathrm{KE}$ is generally confined to the western boundary of the North Pacific, and are also due to the fact that a significant percentage of the boxes depicted in Fig. 4 are poleward of $30^{\circ}$, the critical latitude for propagation of diurnal internal tides.

Differences in potential energy ( $\mathrm{PE}$ - proportional to the square of the vertical displacements, $\hat{\eta}$ ) in each of the first four vertical modes between simulations with and without the synthetic abyssal hills (not shown) reveal a similar pattern to that observed in the changes in KE. For both constituents $M_{2}$ and $K_{1}$, the differences in the SP are small, consistent with the little additional bottom roughness added for that region. In the NA and SA the differences are more significant. The change in the $M_{2}$ potential energy in the NA and SA for modes 2,3 , and 4 increases by up to $10 \%(15 \%)$ in the $1 / 12.5^{\circ}\left(1 / 25^{\circ}\right)$ simulations with the addition of abyssal hills. As with the kinetic energy, the addition of synthetic roughness impacts the potential energy in $K_{1}$ less than it does in $\mathrm{M}_{2}$. 

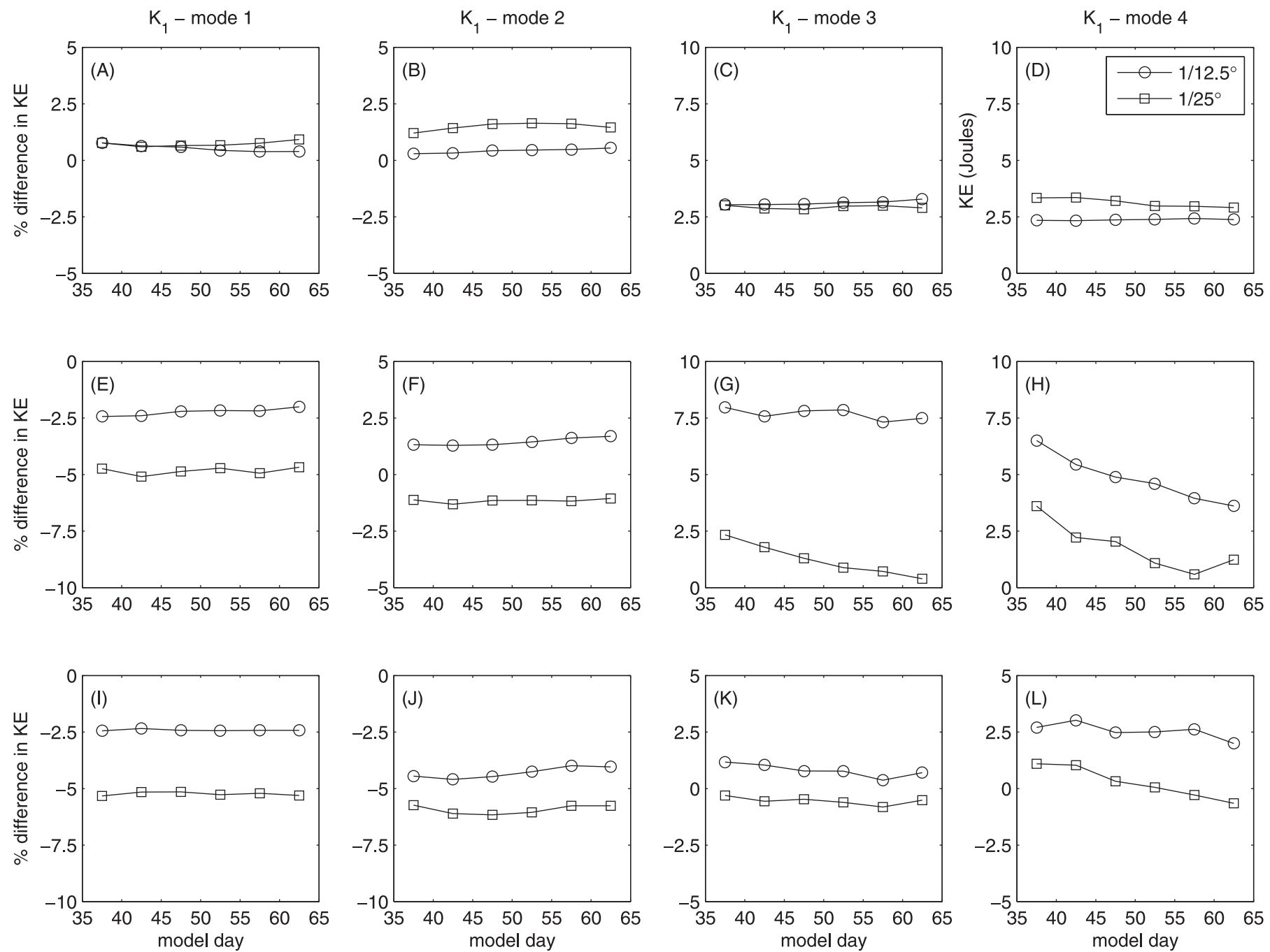

Fig. 18. As in Fig. 17 but for $K_{1}$.

\section{Conclusions}

This paper demonstrates the usage of synthetic abyssal hill maps in numerical ocean models. Current global bathymetric products typically do not resolve features with horizontal wavelengths less than $10-20 \mathrm{~km}$. We have conducted numerical experiments to determine if merging a synthetic abyssal hill representation, having a plausible spectral character, with existing bathymetric products has a significant effect on the resolved motions within a global internal tide model run at horizontal resolutions of $1 / 12.5^{\circ}$ and $1 / 25^{\circ}$ Our method for merging the global bathymetry with a synthetic abyssal hill roughness map allows for the preservation of high-resolution bathymetric data, in limited regions where it exists, through employment of a weighting system based upon identified survey data within the bathymetric product. The method presented to merge the roughness map with bathymetric data is readily adaptable to other models and or model domains including higher-resolution regional models, and to models with more complex forcing than the tide-only simulations studied here.

As we have chosen to use a global ocean model we are, in fact, limited by the vertical and horizontal resolutions that are feasible to use in global numerical models. Use of the synthetic roughness maps in higher resolution regional simulations, which lie beyond the scope of the present study, would likely show substantially larger effects of the roughness than we are able to document with a global model. We find, as Niwa and Hibiya $(2011,2014)$ did, that increasing the resolution of a model that uses existing global bathymetric databases such as SRTM30_PLUS yields an increased small-scale roughness, and hence, an increase in modeled internal tide activity. Indeed, at the resolutions we can afford to run at in the present study, the effect of resolution is larger than the effect of adding synthetic abyssal hill roughness. However, because existing bathymetric datasets do not capture all of the small-scale roughness in the ocean, simply increasing the resolution of numerical models by itself will not capture all of the impacts of smallscale roughness in the ocean. Ultimately to do that, one must have high numerical model resolution and an added synthetic roughness, the latter to make up for the inadequate roughness in available global bathymetric products.

Our results indicate that even with a relatively coarse horizontal model resolution of $1 / 12.5^{\circ}$, which does not adequately resolve abyssal hill structure, and a coarse vertical resolution of 10 layers, there is a measurable impact of abyssal hills on the internal tides within our global model. The abyssal hill impact increases in our higher $\left(1 / 25^{\circ}\right)$ resolution simulations. Globally, the integrated barotropic to baroclinic energy conversion was found to increase by $1 \%(3 \%)$ with the addition of the synthetic abyssal hills structure in $1 / 12.5^{\circ}\left(1 / 25^{\circ}\right)$ simulations. The increase in conversion rates can be up to $16 \%$ in regions having large abyssal hills such as the South Atlantic. Our maps of the increased conversion with the addition of synthetic abyssal hill structure closely resemble those computed in a linear analysis study (Melet et al., 2013), albeit with reduced 
values, due to resolution limitations. The numerical simulations indicate areas of negative (baroclinic-to-barotropic) conversion, which are not found in Melet et al.'s analysis. In addition to changes in the conversion, we have also examined changes in the distribution of internal tidal energy amongst vertical normal modes, with the addition of synthetic small-scale roughness. As with the energy conversion rates, the impact of roughness on vertical mode structure is greater in $1 / 25^{\circ}$ simulations than in $1 / 12.5^{\circ}$ simulations. At $1 / 25^{\circ}$ resolution the increase in $\mathrm{KE}$ in modes 2,3 , and 4 ranges from $6-18 \%$. Similar results are seen in the vertical mode partition of potential energy. Finally, although the addition of abyssal hill roughness does not impact the globally averaged errors of the modelled barotropic tides with respect to altimeter constraints, the abyssal hills do impact the barotropic tidal elevations in some locations by as much as $10 \mathrm{~cm}$.

\section{Acknowledgements}

Data and code sufficient to reproduce the figures and tables in this manuscript is available upon request from the corresponding author as is the original model source code and input data used in the numerical simulations. Original model output used in the production of this manuscript comprises approximately $20 \mathrm{~TB}$ in volume and at time of publication is archived at the Texas Advanced Computer Center. The authors would like to thank the anonymous reviewers who provided many useful comments which helped to improve this manuscript. We thank Harper Simmons for sharing code used for the energy conversion calculations, and, Richard Ray for providing internal tide sea surface elevation estimates along satellite altimeter tracks. PGT, BKA, and JAG acknowledge support from a University of Texas Jackson School of Geosciences Development Grant, Naval Research Laboratory (NRL) contract N00017306-2-C003, Office of Naval Research (ONR) grants N00014-071-0392, N00014-09-1-1003 and N00014-11-1-0487, and National Science Foundation grant OCE-0924481. The work of JKA and $\mathrm{AM}$ on this paper is a component of the Internal-wave driven mixing Climate Process Team led by Professor Jennifer MacKinnon, Scripps Institution of Oceanography, and funded by National Science Foundation grants OCE-0968783 and OCE-0968721 and the National Oceanic and Atmospheric Administration, U.S. Department of Commerce, award NA08OAR4320752. This is NRL contribution NRL/JA/7320-12-1191 and has been approved for public release. This is UTIG contribution number \#3101. The authors acknowledge the Texas Advanced Computing Center (TACC) at The University of Texas at Austin for providing HPC resources that have contributed to the research results reported within this paper. URL: http://www.tacc.utexas.edu. The statements, findings, conclusions, and recommendations are solely the opinions of the authors and do not constitute a statement of policy, decision, or position on behalf of NOAA or the U.S. Government.

\section{References}

Ansong, J.K., Arbic, B.K., Buijsman, M.C., Richman, J.G., Shriver, J.F., Wallcraft, A.J., 2015. Indirect evidence for substantial damping of low-mode internal tides in the open ocean. J. Geophys. Res. Oceans 120, 6057-6071. doi:10.1002/ 2015JC010998.

Arbic, B.K., Garner, S.T., Hallberg, R.W., Simmons, H.L., 2004. The accuracy of surface elevations in forward global barotropic and baroclinic tide models. Deep Sea Res. II 51, 3069-3101.

Arbic, B.K., Wallcraft, A.J., Metzger, E.J., 2010. Concurrent simulation of the eddying general circulation and tides in an ocean model. Ocean Modell. 32, 175-187.

Arbic, B.K., Richman, J.G., Shriver, J.F., Timko, P.G., Metzger, E.J., Wallcraft, A.J., 2012. Global modeling of internal tides within an eddying ocean general circulation model. Oceanography 25, 20-29. doi:10.5670/oceanog.2012.38.

Becker, J. Sandwell, D.T, Smith, W.H.F. Braud, J., Binder, B., Depner, J., Fabre, D. Factor, J., Ingalls, S., Kim, S-H., Ladner, R., Marks, K., Nelson, S., Pharaoh, A., Trimmer, R., Von Rosenberg, J., Wallace, G., Weatherall, P., 2009. Global Bathymetry and Elevation Data at 30 Arc Seconds Resolution: SRTM30_PLUS. Mar. Geodesy 32 (4), 355-371.
Bell, T.H., 1975. Lee waves in stratified flows with simple harmonic time dependence. J. Fluid Mech. 67, 705-722.

Buijsman, M.C., Ansong, J.K., Arbic, B.K., Richman, J.G Shriver, J.F Timko, P.G., Wallcraft, A.J., Whalen, C.B., Zhao, Z., 2016. Impact of parameterized internal wave drag on the semidiurnal energy balance in a global ocean circulation model. J. Phys. Ocean 46 (5), 1399-1419. doi:10.1175/JPO-D-15-0074.1.

Carter, G.S., Fringer, O.B., Zaron, E.D., 2012. Regional models of internal tides. Oceanography 25, 56-65.

Charette, M.A., Smith, W.H.F., 2010. The volume of the earth's ocean. Oceanography 23 (2), 112-114

Chassignet, E.P., Hurlburt, H.E., Metzger, E.J., Smedstad, O.M., Cummings, J.A., Halliwell, G.R., Bleck, R., Baraille, R., Wallcraft, A.J., Lozano, C., Tolman, H.L., Srinivasan, A., Hankin, S., Cornillon, P., Weisberg, R., Barth, A., He, R., Werner, F., Wilkin, J., 2009. US GODAE: global ocean prediction with the HYbrid Coordinate Ocean Model (HYCOM). Oceanography 22, 64-75. doi:10.5670/oceanog.2009.39.

Cummins, P.F., Oey, L.-Y., 1997. Simulation of barotropic and baroclinic tides off Northern British Columbia. J. Phys. Oceanography, 27, 762-781.

de Lavergne, C., Madec, G., Le Sommer, J., Nurser, A.J.G., Naveira Garabato, A.C., 2016. On the consumption of Antarctic bottom water in the abyssal ocean. J. Phys. Oceanography. 46, 635-661. doi:10.1175/JPO-D-14-0201.1.

Dushaw, B.D., Cornuelle, B.D., Worcester, P.F., Howe, B.M., Luther, D.S., 1995. Barotropic and baroclinic tides in the central North Pacific Ocean determined from long-range reciprocal acoustic transmissions. J. Phys. Oceanography. 25, 631-647.

Egbert, G.D., Bennett, A.F., Foreman, M.G.G., 1994. TOPEX/POSEIDON tides estimated using a global inverse model. J. Geophys. Res. 99. doi:10.1029/94JC01894, (C12), 24, 821-24,852.

Egbert, G.D., Erofeeva, S.Y., 2002. Efficient inverse modeling of Barotropic ocean tides. J. Atmos. Oceanic Technol. 19, 183-204

Egbert, G.D., Ray, R.D., 2000. Significant dissipation of tidal energy in the deep ocean inferred from satellite altimetry data. Nature 405, 775-778.

Egbert, G.D., Ray, R.D., 2001. Estimates of M2 tidal dissipation from TOPEX/Poseiden altimeter data. J. Geophys. Res. 106, 22475-22502.

Egbert, G.D., Ray, R.D., 2003. Semi-diurnal and diurnal tidal dissipation from TOPEX/ Poseiden altimetry. Geophys. Res. Lett. 30 (17). doi:10.1029/2003GL017676, 1907.

Egbert, G.D., Ray, R.D., Bills, B.G., 2004. Numerical modeling of the global semidiurnal tide I the present day and in the last glacial maximum. J. Geophys. Res. 109. doi:10.1029/2003JC001973, C03003.

Exarchou, E., von Storch, J.S., Jungclaus, J.H., 2012. Impact of tidal mixing with different scales of bottom roughness on the general circulation. Ocean Dyn. 62, 1545-1563. doi: $10.1007 / \mathrm{s} 10236-012-0573-1$.

Falahat, S., Nycander, J., Roquet, F., Zarroug, M., 2014. Global calculation of tidal energy conversion into vertical normal modes. J. Phys. Ocean 44, 3225-3244. doi:10.1175/JPO-D-14-0002.1.

Foreman, M.G.G., 2004. Manual for Tidal Heights Analysis and Prediction. Institute of Ocean Sciences, p. 58pp.

Garner, S.T., 2005. A topographic drag closure built on an analytical base flux. J. Atmos. Sci. 62, 2302-2315. doi:10.1175/JAS3496.1.

Garrett, C., Kunze, E., 2007. Internal tide generation in the deep ocean. Annu. Rev. Fluid Mech. 39, 57-87. doi:10.1146/annurev.fluid.39.050905.110227.

Goff, J.A., Ma, Y., Shah, A., Cochran, J.R., Sempéré, J.-C., 1997. Stochastic analysis of seafloor morphology on the flank of the Southeast Indian Ridge: the influence of ridge morphology on the formation of abyssal hills. J. Geophys. Res. 102 (B7), 15521-15534. doi:10.1029/97JB00781.

Goff, J.A., 2010. Global prediction of abyssal hill root-mean-square heights from small-scale altimetric gravity variability. J. Geophys. Res. 115 (B12104). doi:10. 1029/2010JC007867.

Goff, J.A., Arbic, B.K., 2010. Global Prediction of abyssal hill roughness statistics for use in ocean models from digital maps of paleo-spreading rate, paleo-ridge orientation and sediment thickness. Ocean Model. 32, 36-43.

Goff, J.A., Jordan, T.H., 1988. Stochastic modeling of seafloor morphology: inversion of sea beam data for second-order statistics. J. Geophys. Res. 93 (B11), 1358913608, doi:10.129/JB093iB11p13589.

Hecht, M.W., Hasumi, H., 2008. Ocean Modelling in an Eddying Regime, 177. American Geophysical Union, Washington, D. C.

Hendershott, M.C., 1972. The effects of solid earth deformation on global ocean tides. Geophys. J. R. Astr. Soc. 29, 389-402.

Kantha, L.H., Tierney, C.C., 1997. Global baroclinic tides. Prog. Oceanogr 40, 163-178.

Lefauve, A., Muller, C., Melet, A., 2015. A three-dimensional map of tidal dissipation over abyssal hills. J. Geophys. Res. Oceans 120, 4760-4777. doi:10.1002/ 2014JC010598

Llewellyn-Smith, S.G., Young, W.R., 2002. Conversion of the barotropic tide. J. Phys. Oceanogr. 32, 1554-1566.

Melet, A., Nikurashim, M., Muller, C., Falahat, S., Nycander, J., Timko, P.G., Arbic, B.K., Goff, J.A., 2013. Internal tide generation by abyssal hills using analytical theory. J. Geophys. Res. 118 (11). doi:10.1002/2013JC009212.

Munk, W., Wunsch, C., 1998. Abyssal recipes II: energetics of tidal and wind mixing. Deep Sea Res. 45, 1977-2010

Niwa, Y., Hibiya, T., 2011. Estimation of baroclinic tide energy available for deep ocean mixing based on three-dimensional global numerical simulations. J. Oceangr. 67, 493-502. doi:10.1007/s10872-011-0052-1.

Niwa, Y., Hibiya, T., 2014. Generation of baroclinic tide energy in a global threedimensional numerical model with different spatial grid resolutions. Ocean Model. 80, 59-73. doi:10.1016/j.ocemod.2014.05.003.

Nycander, J., 2005. Generation of internal waves in the deep ocean by tides. J. Geophys. Res. 110. doi:10.1029/2004JC002487, C10028. 
Ray, R.D., 1998. Ocean self-attraction and loading in numerical tidal models. Mar. Geodesy 21, 181-192.

Ray, R.D., Byrne, D.A., 2010. Bottom pressure tides along a line in the southeast Atlantic Ocean and comparisons with satellite altimetry. Ocean Dyn. 60, 11671176. doi:10.1007/s10236-010-0316-0.

Ray, R.D., Mitchum, G.T., 1996. Surface manifestation of internal tides generated near Hawaii. Geophys. Res. Lett. 23, 2010-2104. doi:10.1029/96GL02050.

Sandwell, D.T., Smith, W.H.F., 2009. Global marine gravity from retracked Geostat and ERS-1 altimetry: ridge segmentation versus spreading rate. J. Geophys. Res. 114 (B01411). doi:10.1029/2008JB02465.

Scott, R.B., Goff, J.A., Naveira-Garabato, A.C., Nurser, A.J.G., 2011. Global rate and spectral characteristics of internal gravity wave generation by geostrophic flow over topography. J. Geophys. Res. 116 C09029.

Shriver, J.F., Arbic, B.K., Richman, J.G., Ray, R.D., Metzger, E.J., Wallcraft, A.J., Timko, P.G., 2012. An evaluation of the barotropic and internal tides in a high resolution global ocean circulation model. J.Geophys. Res. 117. doi:10.1029/ 2012JC008170, C10024

Simmons, H.L., Hallberg, R.W., Arbic, B.K., 2004. Internal wave generation in a global baroclinic tide model. Deep Sea Res. II 51, 3043-3068.

Smith, W.H.F., Sandwell, D.T., 1994. Bathymetric prediction from dense satellite altimertry and sparse shipboard bathymetry. J. Geophys. Res. 99 (B11), 21803-21824.

Smith, W.H.F., Sandwell, D.T., 1997. Global seafloor topography from satellite altimetry and ship depth soundings. Science 277, 1956-1962.

Smith, W.H.F., D.T. Sandwell, D.T., 2004. Conventional bathymetry, bathymetry from space, and geodetic altimetry. Oceanography 17, 8-23.

Stammer, D., Ray, R.D., Andersen, O.B., Arbic, B.K., Bosch, W., Carrère, L., Cheng, Y., Chinn, D.S., Dushaw, B.D., Egbert, G.D., Erofeeva, S.Y., Fok, H.S., Green, J.A.M., Griffiths, S., King, M.A., Lapin, V., Lemoine, F.G., Luthcke, S.B., Lyard, F., Morison, J., Müller, M., Padman, L., Richman, J.G., Shriver, J.F., Shum, C.K., Taguchi, E., Yi, Y., 2014. Accuracy assessment of global barotropic ocean tide models. Rev. Geophys. 52. doi:10.1002/2014RG000450.
St. Laurent, L.C., Garrett, C., 2002. The role of internal tides in mixing the deep ocean. J. Phys. Ocean. 32, 2882-2899.

St. Laurent, L.C., Stringer, S., Garrett, C., Perrault-Joncas, D., 2003. The generation of internal tides at abrupt topography. Deep Sea Res. 50, 987-1003.

Trossman, D.S., Arbic, B.K., Garner, S.T., Goff, J.A., Jayne, S.R., Metzger, E.J., Wallcraft, A.J., 2013. Impact of parameterized lee wave drag on the energy budget of an eddying global ocean model. Ocean Model. 72, 119-142. doi:10.1016/j. ocemod.2013.08.006.

Trossman, D.S., Arbic, B.K., Richman, J.G., Garner, S.T., Jayne, S.R., Wallcraft, A.J., 2016 Impact of topographic internal lee wave drag on an eddying global ocean model. Ocean Model. 97, 109-128. doi:10.1016/j.ocemod.2015.10.013.

Trossman, D.S., Waterman, S., Polzin, K.L., Arbic, B.K., Garner, S.T., NaveiraGarabato, A.C., Sheen, K.L., 2015. Internal lee wave closures: parameter sensitivity and comparison to observations. J. Geophys. Res. Oceans 120, 7997-8019. doi:10.1002/2015JC010892.

Wessel, P., Chandler, M.T., 2011. The spatial and temporal distribution of marine geophysical surveys. Acta Geophys. 59, 55-71. doi:10.2478/s-11600-010-0038-1.

WOCE Data Products Committee, 2002. WOCE Global Data, Version 3.0. WOCE International Project Office, Southampton, UK WOCE Report No. 180/02.

Wright, C.J., Scott, R.B., Ailliot, P., Furnival, D., 2014. Lee wave generation rates in the deep ocean. Geophys. Res. Lett. 41, 2434-2440. doi:10.1002/2013GL059087.

Zaron, E.D., Egbert, G.D., 2006. Verification studies for a z-coordinate primitiveequation model: tidal conversion at a mid-ocean ridge. Ocean Model. 14, $257-$ 278. doi:10.1016/j.ocemod.2006.05.007.

Zilberman, N.V., Becker, J.M., Merrifield, M.A., Carter, G.S., 2009. Model estimates of M2 internal tide generation over Mid-Atlantic ridge topography. J. Phys. Ocean 39, 2635-2651. doi:10.1175/2008JP04136.1. 